\title{
Mathematical formulation and demonstration of a dynamic system-level ship thermal management tool
}

\author{
S. Yang ${ }^{\mathrm{a}, *}$, J. C. Ordonez ${ }^{\mathrm{a}}$, J.V.C. Vargas ${ }^{\mathrm{a}}$, J. Chalfant ${ }^{\mathrm{b}}$, C. Chryssostomidis ${ }^{\mathrm{b}}$ \\ ${ }^{a}$ Department of Mechanical Engineering, Energy and Sustainability Center, and Center for \\ Advanced Power Systems, Florida State University, Tallahassee, FL 32310, USA \\ ${ }^{b}$ MIT Sea Grant Design Laboratory, Massachusetts Institute of Technology, Cambridge, MA \\ 02139, USA
}

\begin{abstract}
This paper presents the mathematical formulation and unique capability of a system-level ship thermal management tool, vemESRDC, developed to provide quick ship thermal responses in early design stages. The physical model combines principles of classical thermodynamics and heat transfer, along with appropriate empirical correlations to simplify the model and expedite the computations. As a result, the tool is capable of simulating dynamic thermal response of an entire ship, characterized by intricate thermal interactions within a complex ship structure, within an acceptable time frame. In this work, vemESRDC is demonstrated through three case studies in which transient thermal responses of an all-electric ship to different ship operation modes, weather conditions, and partial loss of cooling are investigated. The analysis examines particularly the following: (1) the required cooling capacities to maintain each ship component within its design limit; (2) equipment temperature variations with respect to partial cooling loss in battle mode; and (3) the assets of installing seawater heat exchangers to pre-cool deionized freshwater before chillers. For the notional all-electric ship conceived and assessed in this work, the results verify the capability of vemESRDC to capture dynamic thermal interactions between ship-
\end{abstract}

\footnotetext{
${ }^{*}$ Corresponding author.

Email addresses: syang@caps.fsu.edu (S. Yang), ordonez@caps.fsu.edu (J. C. Ordonez), jvargas@caps.fsu.edu (J.V.C. Vargas), chalfant@mit.edu (J. Chalfant), chrys@it.edu (C. Chryssostomidis)
}

Preprint submitted to Advances in Engineering Software

May 17, 2016

(C) 2016. This manuscript version is made available under the Elsevier user license http://www.elsevier.com/open-access/userlicense/1.0/ 
board equipment and their respective surroundings and cooling systems, e.g., the tool provides practical insights into pulse load cooling strategy, and different solutions are obtained for distinct weather conditions. In addition to the case studies performed in this work, vemESRDC can be employed to conduct diverse studies based on which concrete ship thermal management strategies can be formulated in early design stages.

Keywords: all-electric ship, early design stage, ship cooling, ship thermal simulation, vemESRDC, volume element model

\section{Nomenclature}

$\begin{array}{ll}A & \text { heat transfer area }\left(\mathrm{m}^{2}\right) \\ C & \text { heat capacity rate }(\mathrm{W} / \mathrm{K}) \\ c & \text { specific heat }(\mathrm{J} / \mathrm{kg} \mathrm{K}) \\ c_{p} & \text { specific heat at constant pressure }(\mathrm{J} / \mathrm{kg} \mathrm{K}) \\ g & \text { gravity }\left(9.8 \mathrm{~m} / \mathrm{s}^{2}\right) \\ H & \text { total swept height }(\mathrm{m}) \\ h & \text { convective heat transfer coefficient }\left(\mathrm{W} / \mathrm{m}^{2} \mathrm{~K}\right) \\ I & \text { global solar irradiance }\left(\mathrm{W} / \mathrm{m}^{2}\right) \\ L & \text { total swept length }(\mathrm{m}) \\ l & \text { length or width }(\mathrm{m}) \\ \dot{m} & \text { mass flow rate }(\mathrm{kg} / \mathrm{s}) \\ n & \text { total number } \\ P r & \text { Prandtl number } \\ p_{v, i} & \text { partial vapor pressure }(\mathrm{Pa}) \\ p_{v s} & \text { water vapor pressure }(\mathrm{Pa}) \\ \dot{Q} & \text { heat transfer rate }(\mathrm{W}) \\ R a_{H} & \text { Rayleigh number } \\ R e_{L} & \text { Reynolds number } \\ T & \text { temperature }(\mathrm{K}) \\ T_{i 0} & \text { initial temperature }(\mathrm{K}) \\ & \end{array}$




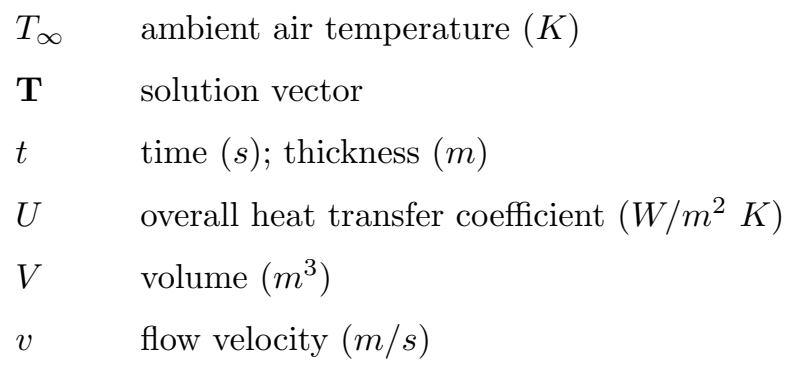




$\begin{array}{ll}\text { out } & \text { outlet } \\ r & \text { ratio } \\ \text { rad } & \text { radiation } \\ s & \text { south } \\ s w & \text { seawater } \\ t & \text { top } \\ w & \text { west; wall } \\ z & \text { zone; z-direction }\end{array}$

Greek letters

$\begin{array}{ll}\alpha & \text { absorptivity } \\ \alpha_{T} & \text { thermal diffusivity }\left(\mathrm{m}^{2} / \mathrm{s}\right) \\ \beta & \text { thermal volumetric expansion }\left(\mathrm{K}^{-1}\right) \\ \varepsilon & \text { relative error; emissivity } \\ \varepsilon_{h x} & \text { heat exchanger effectiveness } \\ \nu & \text { kinematic viscosity }\left(\mathrm{m}^{2} / \mathrm{s}\right) \\ \rho & \text { density }\left(\mathrm{kg} / \mathrm{m}^{3}\right) \\ \sigma & \text { Stefan-Boltzmann constant }\left(5.67 \times 10^{-8} \mathrm{~W} / \mathrm{m}^{2} \mathrm{~K}^{4}\right) \\ \phi & \text { relative humidity } \\ \phi_{i 0} & \text { initial relative humidity }\end{array}$

\section{Introduction}

System-level thermal analysis of an all-electric ship is an essential procedure during its early design stages for devising effective thermal management strategies, to satisfy ship cooling requirements in all conceivable operation modes and scenarios. In an all-electric ship, devices integrated for control, power, propulsion, and weaponry are predicted to dissipate considerable amounts of heat [1 5]. In [3 5], the authors report the notional pulsed weapon system, radar, 
and vital loads (e.g. sensors, data processors, etc.) to generate heat at approximate rates of 2.8 MW, 3.5 MW, and 0.76 MW, respectively. Similarly, non-vital loads and personnel are also estimated to significantly contribute to the total heat generation. As a result, Zerby [2] anticipates $700 \%$ increase in the overall cooling capacity of the future all-electric ship to ensure proper operation of all equipment within the ship. These values, however, do not reflect the transient nature of each equipment in different ship operation modes and possible cooling losses, and therefore, the global performance of an actual all-electric ship is expected to depend more heavily on dynamic ship thermal responses.

In order to study ship thermal responses and its cooling network at the system level, reduced-order mathematical model and simulation tool, capable of addressing the transient nature of every ship component at a low computational cost, is required for reliable assessments. Such a tool can be employed to promote concrete thermal management strategies and improve ship survivability in all conceivable operation modes by satisfying its cooling requirements. In addition, the tool can be used to capture and predict ship thermal behaviors in cases such as system failures, e.g., partial cooling loss. In efforts to comply with these objectives, several studies on dynamic system-level thermal response of an all-electric ship have been conducted previously by means of simple mathematical models, and a few representative ones are discussed in this brief review.

Chiocchio et al. [6] conducted a preliminary analysis for future real-time, system-level hardware-in-the-loop (HIL) simulations. The primary objective of this study was to validate a mathematical model developed for a $5 \mathrm{MW}$ rotating machinery test facility using the experimental data. Subsequently, the authors analyzed transient thermal behaviors of two 2.5 MW induction motors and their speed drives in conjunction with the cooling network. Factor screening and uncertainty propagation were employed to validate the model and determine which uncertain parameters had the largest effect on the simulation results.

Ruixian et al. [7, 8] investigated an integrated approach to performing thermal-electrical coupled co-simulation of integrated power and cooling systems of future all-electric ship. The authors assessed the temperature variation 
of power conversion module (PCM) under a step change of the service load [7. Furthermore, the study aimed to evaluate the transient interaction between power and thermal subsystems using a hybrid electrical power model and chilled water system developed on the virtual test bed (VTB) platform. Simulation results demonstrated the ability of the model to capture significant system dynamics while providing insights into the optimal system configurations and operating parameters. Similarly, Hewlett and Kiehne [9] elaborated and validated a dynamic thermal modeling and simulation (DTMS) framework for its potential use as a shipboard HVAC optimization tool. The authors implemented two non-traditional shipboard cooling concepts in DTMS and compared them to current chilling systems. These advanced cooling systems not only resulted in immediate power savings relative to baseline models, but they provided potential for simulation of dynamic reconfiguration for future all-electric ship.

Backlund et al. [10] developed total ship-zonal distribution models of electric power, chilled water, and refrigerant air systems. The authors presented a highly reconfigurable modeling approach that enabled users to configure shipboard electrical, chilled water, and refrigerated air distribution architecture. Furthermore, the paper advocated the use of metamodels and discrete variable classifiers as a mean to provide fast responses. Sanfiorenzo [11] devised a cooling system design tool (CSDT) to model the cooling network in the notional all-electric ship, and evaluated the overall ship cooling capacity, pressure drops in the pipe network, and temperature variation of each thermal load. CSDT was also capable of visualizing the pipe network (i.e., joints, bends, and valves) within the predefined ship geometry.

According to the literature review, mathematical models and simulation tools have already been developed to address system-level ship thermal behaviors in the trainset regime. Several of these works also exhibited component-level thermal analyses under dynamic heat loads and cooling capacities, and proposed novel approaches to optimize the cooling network. Previous studies, however, failed to fully address the intricate energy interactions between equipment and their surroundings within the ship, in which case the heat transfer between an 
equipment and its adjacent components (e.g. another equipment or ambient air) may have significant effect on the cooling network design. Furthermore, these tools were incapable of portraying complex ship geometry constituted of hull, superstructure, and multiple bulkheads and decks, and such limitations made zonal and compartmental ship thermal analysis rather challenging. Moreover, most of these works emphasized the validation aspect of their simulation tools rather than performing dynamic thermal simulations of the ship with realistic operational parameters, ambient conditions, and thermal loads anticipated in an actual ship.

Based on these observations, modeling, simulation, and visualization of system-level thermal interactions within a complex ship structure, under different operation modes and unexpected system failures, still remain as challenges to overcome. Therefore, the objective of this paper is to present the mathematical formulation and unique capability of a previously developed system-level ship thermal management tool, vemESRDC, of addressing these challenges by simulating dynamic ship thermal responses characterized by intricate thermal interactions. The tool is demonstrated through three case studies in which transient thermal responses of an all-electric ship to three ship operation modes, two extreme weather conditions, and partial loss of cooling are investigated; all subject to realistic ship operational parameters, ambient conditions, and thermal loads. In particular, this work examines the following: (1) the required cooling capacities to maintain each ship equipment within its design limit in shore, cruise, and battle modes; (2) equipment temperature variations with respect to partial loss of cooling in battle mode; and (3) the effects of installing seawater heat exchangers (SWHX) to pre-cool deionized freshwater before chillers. Two extreme weather conditions have been simulated by assuming two fictitious mission locations with contrasting ambient air and seawater temperatures.

vemESRDC is a volume element model (VEM)-based ship thermal management tool developed to quickly provide thermal responses of a ship during its early design stages [12 14]. The tool has been experimentally validated previously with Power Electronics Building Blocks [15] and in different context 
using thermal data from an Off-Grid Zero Emissions Building [16] vemESRDC comprises two subprograms: the mesh generation tool and the numerical solver. The ship mesh generation tool employs ray tracing algorithms to construct the computational grid with hexahedral elements, i.e., volume elements (VEs). In the solver, fundamental laws of heat transfer and thermodynamics are applied to each $\mathrm{VE}$, and the resulting system of nonlinear ordinary differential equations (ODEs) is solved with respect to time using an appropriate numerical method. Figure 1 shows the flowchart of vemESRDC. The tool has been amended from its previous version [17, 18] to enhance its computational efficiency by implementing an implicit solver, and to account for ship cooling strategies represented by combinations of seawater, deionized freshwater, and conditioned air. The program is written in Fortran.

\section{2. vemESRDC mesh generation}

The computational domain in vemESRDC is discretized into a coarse mesh constituted of lumped control volumes. The VEM mesh generation process is

as follows: (1) read a Stereolithography (STL) file and extract ship geometric information; (2) read user-input text files including: the total desired number of volume elements in $\mathrm{x}, \mathrm{y}$, and $\mathrm{z}$ directions, number of bulkheads and decks with predefined thicknesses, and spatial location, physical dimensions, and properties of ship equipment; (3) generate an enclosing hexahedral mesh block that comprises the entire ship; (4) obtain the final ship mesh via ray tracing algorithm [19]; (5) allocate equipment inside the ship and assign physical properties to each volume element; and (6) export the mesh information to the numerical solver and VisIt visualization tool 20]. Only a brief description of the mesh generation procedures is included in this paper; details on vemESRDC mesh generation strategy can be found in [21]. 


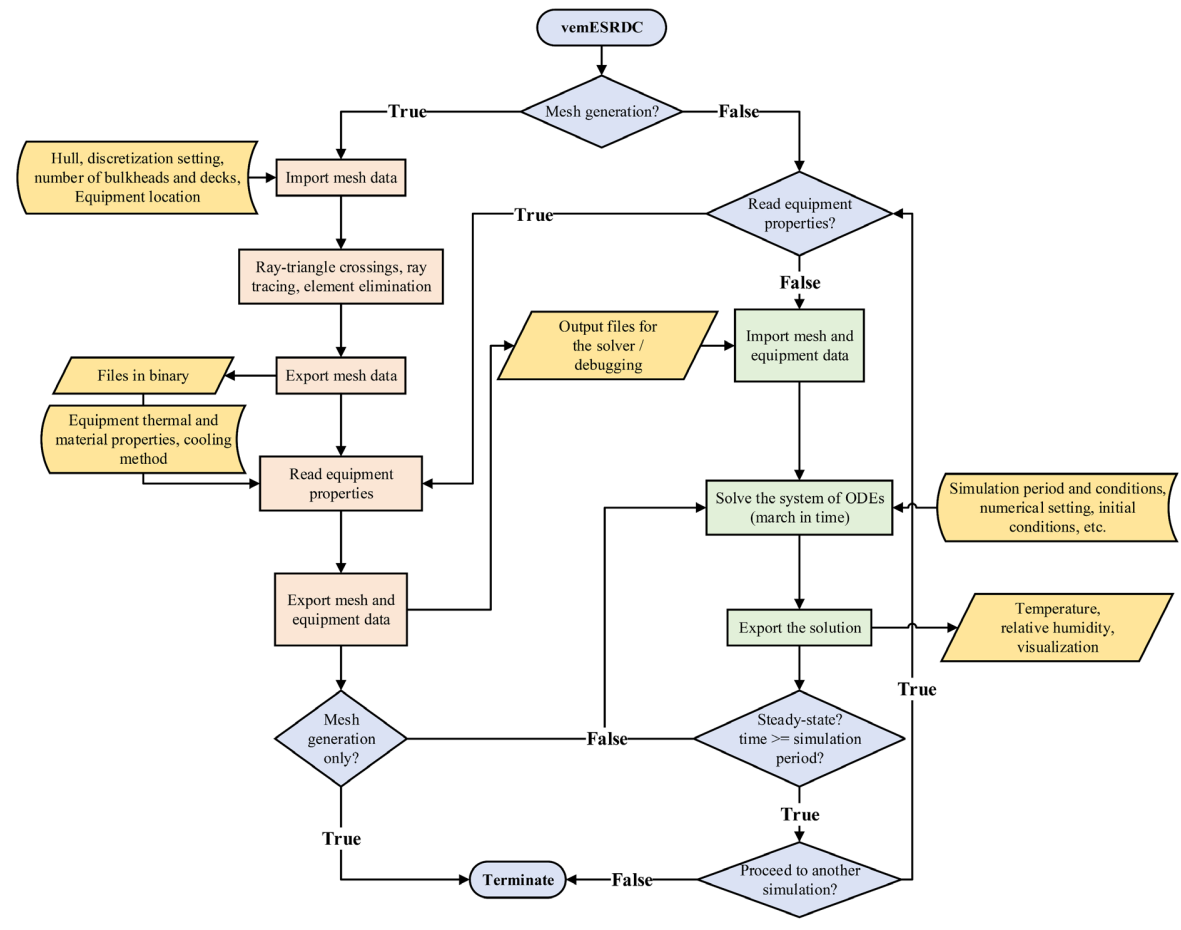

Figure 1: vemESRDC flowchart.

\subsection{Geometry meshing}

vemESRDC reads an STL file and extracts vertices and facet data of the triangles constituting the ship geometry. Once the extraction of geometric information completes, the tool finds the extreme values of $\mathrm{x}, \mathrm{y}$, and $\mathrm{z}$, which are used to construct the enclosing hexahedral mesh block that comprise the entire ship. This work considers a notional all-electric ship hull, termed Notional Destroyer, with four zones and eleven levels separated by three bulkheads in the $\mathrm{x}$-direction and ten decks in the z-direction with predefined thickness of $0.4 \mathrm{~m}$ and $0.2 \mathrm{~m}$, respectively. The CAD drawing and schematic diagram of the Notional Destroyer under analysis are illustrated in Figure 2 and 3 respectively. The number of VEs in each spatial direction is arbitrarily chosen for the first mesh, then it is successively refined until an independent mesh is obtained 
according to the following criterion [22]

$$
\varepsilon_{m e s h}=\frac{\left|\|\mathbf{T}\|_{m e s h, 1}-\|\mathbf{T}\|_{m e s h, 2}\right|}{\|\mathbf{T}\|_{m e s h, 1}} \leq 10^{-3}
$$

where $\varepsilon_{m e s h}$ is the mesh refinement relative error; $\mathbf{T}$ is the solution vector in the entire domain; and mesh,1 and mesh,2 are refined and more refined meshes, respectively.

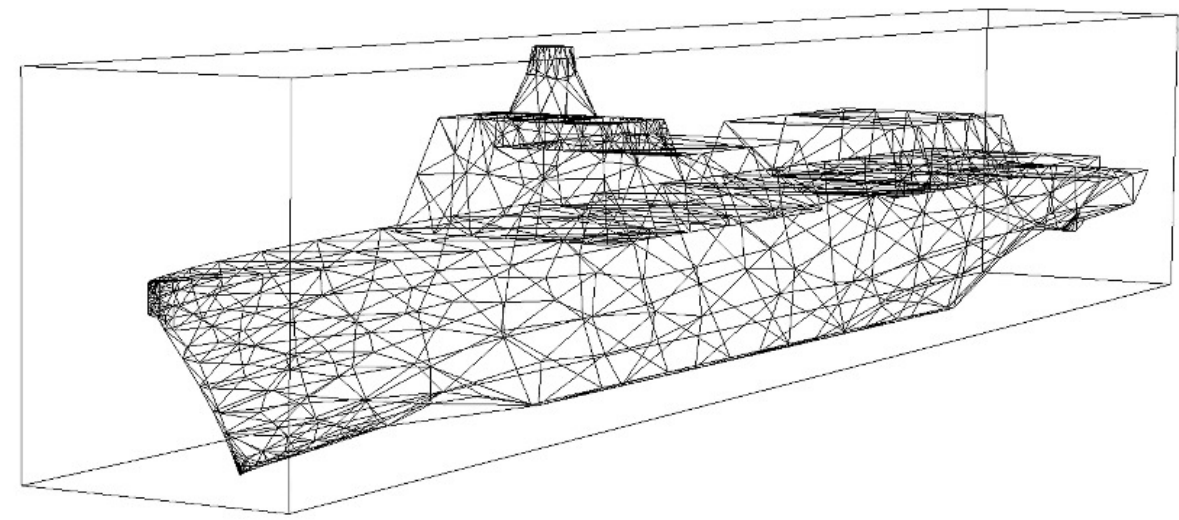

Figure 2: CAD drawing of a Notional Destroyer.

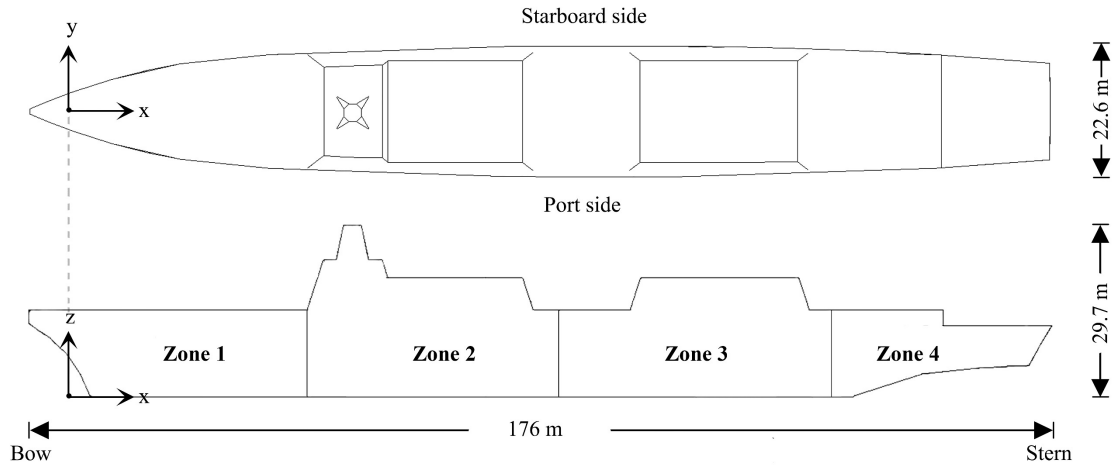

Figure 3: Schematic diagram illustrating the dimensions, origin, and zonal divisions of the Notional Destroyer. 
The final ship mesh depicted in Figure 4 is obtained by eliminating all VEs lying outside of the actual ship geometry from the enclosing mesh block. Such a task is realized by implementing ray-crossings and ray-triangle intersection algorithms [21].

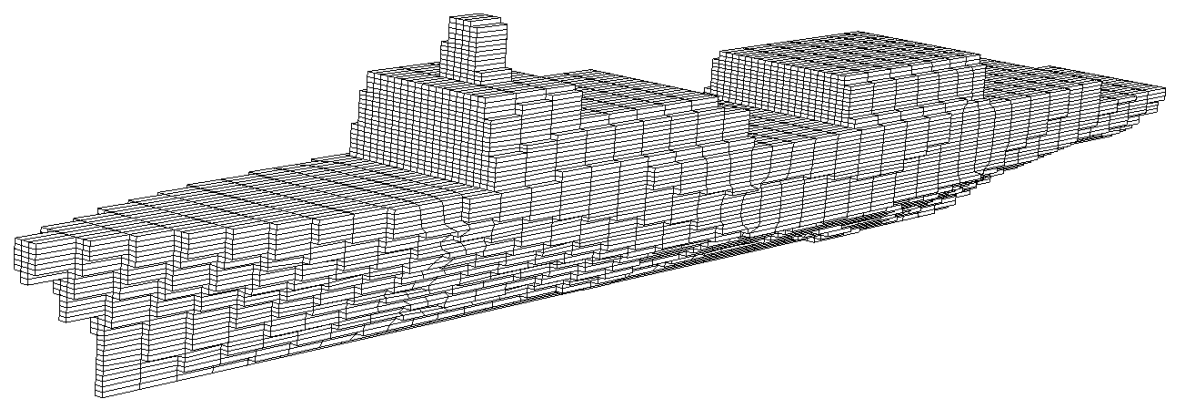

Figure 4: Final mesh of the Notional Destroyer with three bulkheads and ten decks.

\subsection{Equipment and VE property allocation}

After the geometry meshing is finished, additional steps are performed to facilitate the integration of the final mesh with the solver. In vemESRDC, every volume element represents a control volume that consists of a bounding box containing a fluid (e.g., air), solid (i.e., bulkheads, decks, or equipment), or mixture (solid+fluid), and each solid component is placed in one or more volume elements according to its physical dimensions. Similarly, the following interactions and boundaries are possible in vemESRDC: (1) fluid-fluid; (2) fluid-mixture; (3) fluid-solid; (4) solid-solid; (5) solid-mixture; (6) mixture-mixture; (7) solidcomputational domain boundary; (8) fluid-computational domain boundary; and (9) mixture-computational domain boundary.

In order to quantify the energy transfer between elements, vemESRDC searches for neighboring elements for each volume element at its north, south, east, west, top and bottom faces; then identifies each according to the three possible element types previously described: fluid, solid, or mixture. All volume elements contain fluid (air) by default unless solid or mixture element types are 
specified.

\subsection{Output files}

vemESRDC mesh generation tool generates three output files: (1) a Visualization Toolkit (VTK) file that can be imported to VisIt for mesh visualization and text files containing (2) physical properties of every volume element and (3) its coordinates, nodes, and adjacent element numbers. These files are imported by the solver to construct an ODE for each VE in the mesh.

\section{Mathematical formulation (solver)}

vemESRDC combines simplified physical model with the adopted finite volume scheme for the numerical discretization of differential equations. The model takes into account the existence of internal heat sinks (or sources) and the heat transfer across all element faces, by conduction, convection, and radiation. This is possible through the use of empirical heat transfer correlations available in literature to simplify the modeling and expedite the computations.

Each VE interacts with its adjacent elements according to the energy balance applied to the cell as follows:

$$
\frac{d T_{i}}{d t}=\frac{1}{(\rho V c)_{i}}\left[\sum_{j=e, w, t, b, n, s} \dot{Q}_{j}+\dot{Q}_{g e n}+\dot{Q}_{c o n v}\right]_{i}
$$

where $1 \leq i \leq N$, with $N$ being the total number of elements in the mesh, $T_{i}$ is the temperature of $\mathrm{VE} i, \rho$ is the density of the material inside the VE (fluid and/or solid), $V$ the total element volume, c is either the specific heat of the solid/liquid or the specific heat at constant volume of the gas inside the VE, $\dot{Q}_{j}$ is the heat transfer rate across east, west, top, bottom, north, south faces of VE $i$ by conduction, natural and forced convection, and radiation, $\dot{Q}_{g e n}$ is the heat sink or source inside the element, and $\dot{Q}_{c o n v}$ is the net heat transfer rate collected/rejected through convection by one or more fluid streams (e.g., deionized freshwater, seawater, or air) that flow through the VE $i$. Figure 5 shows a typical VE with heat transfer interactions through all six faces. 


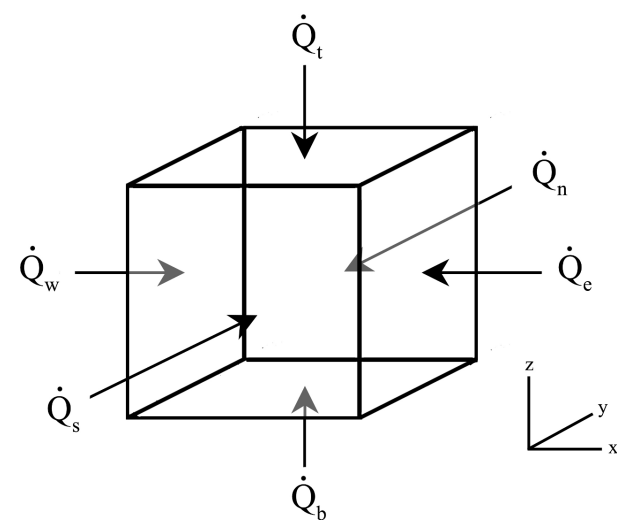

Figure 5: Volume element with heat transfer interactions.

\subsection{Heat transfer across the element faces}

Empirical correlations [23, 24] are utilized to calculate the heat transfer rates across the faces of each VE. As described in Section 2.2, nine energy interaction types are accounted in the present formulation, and each element has four side faces in addition to top and bottom faces as shown in Figure 5 For each face, there are two possible boundaries: the face is either in contact with the computational domain boundary or with another element.

\subsubsection{Faces in contact with the computational domain boundary}

The element may have solid, fluid, or mixture in it while one or more faces may be in contact with the computational domain boundary. Heat transfer is taken into account by conduction, convection and radiation as appropriate. The radiation heat transfer rate across the face $j$ of element $i$ is calculated by:

$$
\dot{Q}_{r a d, i, j}=A_{i, j}\left[\alpha_{j} I-\varepsilon_{j} \sigma\left(T_{i, j}^{4}-T_{e x t}^{4}\right)\right]
$$

where the first term in the brackets represents the average global solar irradiance $I$ [25] absorbed by the face $j$ when there is sun incidence; $T_{\text {ext }}=T_{\infty}$ (exterior air temperature) or $T_{e x t}=T_{s w}$ (other external surrounding fluid temperature, e.g., seawater in this work); $\alpha$ and $\varepsilon$ are the element face absorptivity and emissivity, respectively; $\sigma$ is the Stefan-Boltzman constant and $A_{i, j}$ is the face area. It is also assumed that $I=0$ at the surfaces in contact with seawater. 
The total heat transfer rate (radiation, conduction, and convection) across the face $j$ of element $i$ is therefore computed as follows:

$$
\dot{Q}_{i, j}=\dot{Q}_{r a d, i, j}+U_{i, j} A_{i, j}\left(T_{e x t}-T_{i}\right)
$$

where the global heat transfer coefficient, $U_{i, j}$, for solid VE is given by:

$$
U_{i, j}=\left(\frac{l_{i, j}}{2 k_{i}}+\frac{t_{w}}{k_{w}}+\frac{1}{h_{e x t}}\right)^{-1}
$$

whereas for fluid (e.g., air) VE is:

$$
U_{i, j}=\left(\frac{1}{h_{i n t}}+\frac{t_{w}}{k_{w}}+\frac{1}{h_{e x t}}\right)^{-1}
$$

in which $l_{i, j}$ is either the VE length or width, $k_{i}$ is the VE thermal conductivity, $t_{w}$ and $k_{w}$ are the wall thickness and thermal conductivity, respectively, and $h_{\text {int }}$ and $h_{\text {ext }}$ are the interior and exterior convective heat transfer coefficients, respectively.

Appropriate convective heat transfer coefficient, $h$, is calculated for each corresponding convection type. For natural convection, $h_{n c}$ is computed as [23, 24]:

$$
h_{n c}=\frac{k_{f}}{H}\left[0.825+\frac{0.387 R a_{H}^{1 / 6}}{\left(1+(0.492 / P r)^{9 / 16}\right)^{8 / 27}}\right]^{2}
$$

where $k_{f}$ is the fluid thermal conductivity, $\operatorname{Pr}$ is the Prandtl number of the fluid, and $R a_{H}=g \beta H^{3}\left|T_{a d j, i}-T_{i}\right| /\left(\alpha_{T} \nu\right)$ is Rayleigh number in which $g$ is gravity, $\beta$ is fluid coefficient of thermal volumetric expansion, $\alpha_{T}$ is the fluid thermal diffusivity, $\nu$ is the fluid kinematic viscosity, $T_{a d j, i}$ is the adjacent element temperature or the exterior temperature, and $H$ is the total solid swept height under analysis. Eq. 7 is valid for the entire Rayleigh number range: laminar, transition, and turbulent, with the fluid properties evaluated at the film temperature, i.e., $T_{f i l m}=\left(T_{a d j, i}+T_{i}\right) / 2$ for all Prandtl numbers [26].

In case of forced convection, $h_{f c}$ is given by:

$$
\begin{array}{rr}
h_{f c}=\frac{k_{f}}{L}\left(0.064 \operatorname{Pr}^{1 / 3} \operatorname{Re}_{L}^{1 / 2}\right) & \text { for } R e_{L}<5 \times 10^{5} \\
h_{f c}=\frac{k_{f}}{L}\left[0.037 \operatorname{Pr}^{1 / 3}\left(\operatorname{Re}_{L}^{4 / 5}-23550\right)\right] & \text { for } R e_{L}>5 \times 10^{5}
\end{array}
$$


where $R e_{L}=v_{f} L / \nu$ in which $v_{f}$ is the fluid velocity and $L$ is the total solid swept length under consideration.

\subsubsection{Side faces in contact with another element}

The present model does not account for the flow across a fluid-fluid boundary in the horizontal direction; only the flow in the vertical direction is considered. While the assumption that there is a sudden temperature change from one VE to the next does not appear to mimic reality, such an assumption is considered acceptable in the present simulation environment with a large number of discretized volume elements, e.g., system-level simulations. In many cases, VEs are separated by bulkheads, and in the remaining cases, the flow from one element to the next is accounted for through the forced convection calculations in the vertical direction as well as heat transfer across element faces.

If the interface is fluid-fluid or solid-solid, only conduction takes place between adjacent elements assuming no horizontal flow. The other possibility is a fluid-solid equipment interaction between the two elements, in which case heat transfer across the element face is ruled by convection. For the fluid-fluid contact, assuming no fluid flow across the side faces, the heat transfer rate across side face $l$ of element $i$ is given by:

$$
\dot{Q}_{i, l}=-U_{i, l} A_{i, l}\left(T_{i}-T_{a d j}\right)
$$

where $l=e, w, n, s$ and the overall heat transfer coefficient is computed as:

$$
U_{i, l}=\frac{2 k_{f}}{l_{m, i}+l_{m, a d j}}
$$

where $l_{m, i}$ and $l_{m, a d j}$ are either the VE length or width, according to the direction index $m$ ( $x$ or $y$ direction according to Figure 5) which depends on whether the $i$ th or its adjacent element side face is east/west or north/south, respectively.

For the solid-solid contact, the heat transfer rate across side faces is also obtained from Eq. 9, in which:

$$
U_{i, l}=\frac{2 k_{i} k_{a d j}}{l_{m, i} k_{a d j}+l_{m, a d j} k_{i}}
$$


where $k_{i}$ and $k_{a d j}$ are thermal conductivity of element $i$ and its adjacent element, respectively. When the contact is of the type fluid-solid, convection takes place and Eq. 9 is employed. Appropriate convective heat transfer coefficient, $h_{l}$, is computed as in Eq. 7 and 8 and the overall heat transfer coefficient is given by:

$$
U_{i, l}=\frac{2 k_{c} h_{l}}{2 k_{c}+l_{m, c} h_{l}}
$$

where $c$ indicates a solid element.

\subsubsection{Top/bottom faces in contact with another element}

The heat flux across face $j$ of a fluid element $i$, that is in contact with another element containing fluid, is given by:

$$
\dot{Q}_{i, j}=\dot{m}_{i, j} c_{p, f}\left(T_{a d j}-T_{i}\right)
$$

where $j=t, b$ and $\dot{m}_{i, j}=\rho_{f} v_{i} A_{i, j} / 2$. For natural convection, the estimated fluid

velocity crossing the element face is $v_{i}=\alpha_{T}\left(g \beta\left|T_{a d j}-T_{i}\right| H / \alpha_{T} \nu\right)^{1 / 2}$, which is a natural convection representative scale 23. It is also assumed that half of the element top/bottom face is crossed by the fluid in the upward direction, and the other half in the opposite direction. In case of forced convection, the estimated fluid velocity crossing the element face, $v_{i}$, is a known parameter from the air conditioning system design.

The heat transfer rate across the top/bottom element faces with fluid-solid interactions follows from Eq. 9 with $l=t, b, . \quad U_{i, l}$ is computed with Eq. 12 and $l_{m, c}$ is replaced by $l_{z, c}$, where $z$ indicates z-direction according to Figure 5 Likewise, in case of solid-solid interaction, the heat transfer rate also follows from Eq. 9, with $l=t, b . U_{i, l}$ is given by Eq. 12 and the lengths $l_{m, i}$ and $l_{m, a d j}$ are replaced by $l_{z, i}$ and $l_{z, a d j}$, respectively.

\subsubsection{Mixture elements}

According to Section 2.2, VEs containing both fluid and solid or different types of solid or fluid are treated as mixture elements. These elements may interact with the computational domain boundary, other solid, fluid, or mixture 
elements. Two possible methods are available to address VEs with mixed entities with discrepancies in their physical and mesh volumes:

1. Treat VE contents as a homogenous mixture of entities and calculate uniform properties for the $\mathrm{VE}$ using a weighted average proportional to the mass of each entity, or

2. Treat VE contents as a group of distinct entities, and separately apply the differential equation to each.

The second alternative requires more differential equations to be solved, therefore increasing the overall computational time. As a result, the first alternative has been employed for vemESRDC, where equivalent specific heat $\left(c_{e q}\right)$, density $\left(\rho_{e q}\right)$, and thermal conductivity $\left(k_{e q}\right)$ for components are estimated as follows [27, 28]:

$$
\begin{array}{r}
c_{e q}=\frac{\sum_{i=1}^{n} m_{i} c_{i}}{m_{c o}} \\
\rho_{e q}=\frac{V_{R}}{V_{m}} \rho_{R} \\
k_{e q}=\left(\frac{V_{R}}{V_{m}}\right)^{\frac{1}{3}} k_{R}
\end{array}
$$

where $m_{i}$ is the mass of the material $i$ in the component composed by $n$ material types; $m_{c o}$ is the component mass; $V_{R} / V_{m}$ is the ratio between the component physical and mesh volumes; and $\rho_{R}$ and $k_{R}$ are the actual component weighted average density and thermal conductivity, respectively.

The net heat transfer rate collected/rejected via convection by one or more fluid streams crossing volume element $i$, i.e., $\dot{Q}_{c o n v, i}$ in Eq. 2 , accounts for the components and their cooling strategies, which are reported in detail in Section 4.

\subsection{Relative humidity}

The system of ODEs defined by Eq. 2 formulates the initial value problem to be solved, depicting the temperature field inside the integrated system at 
any instant, for a given initial condition $T_{i 0}$. The relative humidity at each air element (relative humidity field) follows from the temperature field by assuming a known initial relative humidity condition, $\phi_{i 0}$. First, the initial vapor pressure is calculated as follows:

$$
p_{v, i}=\phi_{i 0} p_{v s}\left(T_{i 0}\right)
$$

where $p_{v, i}$ and $\phi_{i 0}$ are partial vapor pressure and initial relative humidity of element $i$, and $p_{v s}\left(T_{i 0}\right)$ is the water saturation pressure at $T_{i 0}$.

Presumed is the constant absolute humidity in each volume element during the entire simulation, based on the assumption that the atmospheric pressure and vapor pressure variations are negligible in a controlled environment within the ship, e.g., with closed windows. Therewith, the relative humidity at each element that contains air is computed from:

$$
\phi_{i}=\frac{p_{v, i}}{p_{v s}\left(T_{i}\right)}
$$

where $\phi_{i}$ is relative humidity of element $i$ and $p_{v s}\left(T_{i}\right)$ is water saturation pressure at temperature of element $i . \phi_{i}=0$ when the element contains a solid or liquid.

\subsection{Numerical method}

Numerical method for a particular problem is selected based on the desired accuracy and stability, as well as the computational time. A wide range of explicit and implicit methods of different orders are available for solving a system of ODEs 29]. The most appropriate numerical method is chosen for vemESRDC to integrate the system in time based on the following three numerical properties: stability, accuracy, and convergence. If a steady-state solution is desired, the time derivative term in Eq.2 2 is neglected and the resulting system of $N$ nonlinear algebraic equations is solved using Newton-Raphson method [30].

Previous versions of vemESRDC employed Runge-Kutta-Fehlberg (RKF45) [18] and Backward Euler (BE) [16] methods to solve the system of nonlinear ODEs. RKF45 is an explicit numerical method capable of obtaining transient solutions faster than many other one-step explicit methods by adapting the time 
step size based on the $5^{\text {th }}$ order error estimation 31. However, RKF45 becomes unstable in solving stiff ODEs unless the time step size $\Delta t$ is small relative to the time scale of the rapid transient [32, i.e., $\Delta t_{\text {stability }} \ll \Delta t_{\text {accuracy. }} \mathrm{BE}$, on the other hand, is L-stable [29] and thus it satisfies the stability condition with a larger $\Delta t$, i.e., $\Delta t_{\text {stability }} \gg \Delta t_{\text {accuracy }}$. Nonetheless, BE is a first order method which provides less accurate solutions than RKF45 unless significantly small $\Delta t$ is selected. BE also demands high computational cost by requiring the new approximation to be solved at every time step. Therefore, a high-order numerical method with a large stability region is sought to obtain accurate solutions while preventing unphysical oscillation due to numerical dispersion.

According to these criteria, Backward Differentiation Formula (BDF), also known as Gear's method [33], was selected as the most suitable numerical method for vemESRDC. BDF is an implicit linear multi-step method that is widely implemented to solve stiff systems of ODEs. In addition, adaptive timestep controller for BDF was developed previously to expedite the computing process 34. As a result, dynamic-order BDF with an adaptive time-step controller was implemented into vemESRDC in order to enhance its computational efficiency, defined as accuracy achieved per unit execution time, by solving the stability issue (i.e., implicit) and quickly providing accurate solutions with a larger $\Delta t$. The numerical convergence is verified as described in [34 while steady-state is obtained when the Euclidean norm of the difference between the current and the previous solution vectors is equal or less than the prescribed tolerance, e.g., $10^{-3}$.

\section{Ship cooling strategies}

The Notional Destroyer is divided into four zones where each zone is cooled separately, with combinations of seawater, deionized freshwater, and conditioned air. From this point on, deionized freshwater is simply referred to as freshwater for the brevity of our discussion. In vemESRDC, eight VE types are defined in accordance with the content and the proposed cooling method: (0) only air; 
(1) pure solid (no dedicated cooling); (2) seawater heat exchanger (SWHX);

(3) chilled water unit (CWU); (4) air conditioning unit (ACU); (5) freshwatercooled components (FWC); (6) auxiliary seawater-cooled components (SWC); and (7) air-conditioned components (AC). As mentioned in Section 2.2, all volume elements contain air by default; unless solid components (e.g., equipment, bulkheads, and decks) are assigned by the user along with its corresponding VE type. VE types and cooling strategies available in vemESRDC are summarized in Figure 6 .

\section{Volume Element Types}

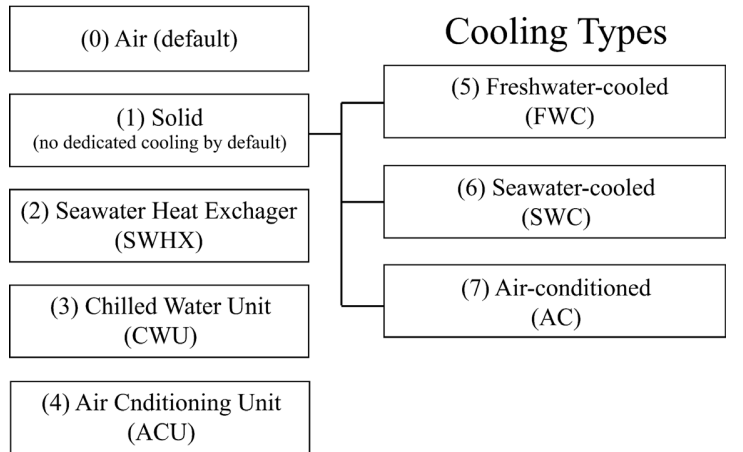

Figure 6: Volume element types and available cooling methods.

Figure 7 exhibits the distribution of thermal loads throughout the four thermal zones within the Notional Destroyer, along with their cooling strategies and heat generation rates in battle mode. In Figure 7, large thermal loads (e.g., railgun, laser, radar, gas turbines, etc.) are depicted individually whereas small loads are lumped together as vital and non-vital loads for simplicity.

\subsection{Seawater heat exchanger (SWHX)}

Seawater heat exchangers (SWHXs) are installed to pre-cool the freshwater before it enters chilled water units (CWUs). This is an effective way to minimize the cooling capacity required by the $\mathrm{CWU}$ as long as the seawater temperature is below freshwater temperature at the SWHX inlet. The effectiveness-NTU method is used to estimate the heat exchanger effectiveness, which can be ap- 

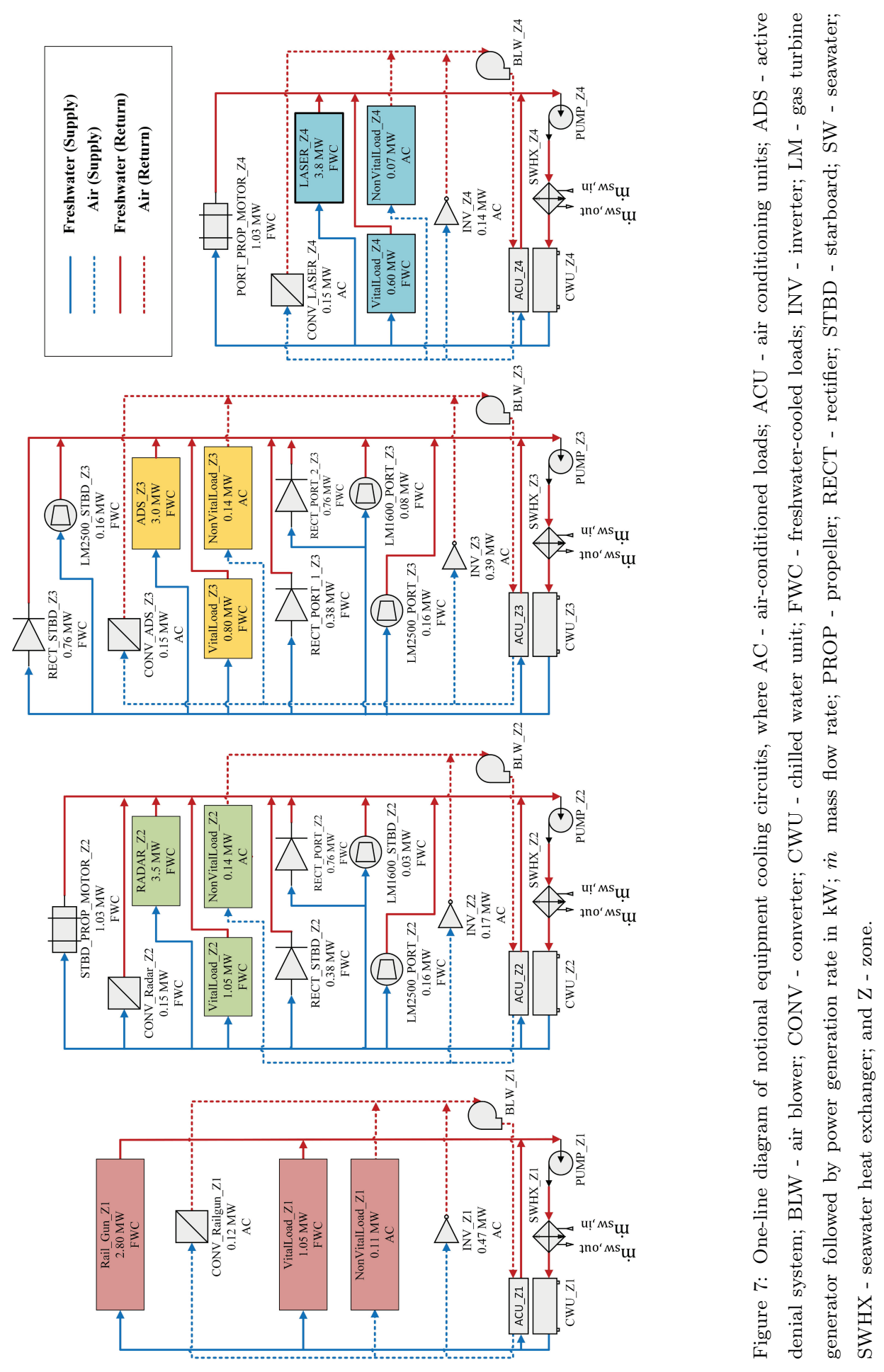
plied to any type of compact heat exchanger [35]. Assuming a counter-flow compact heat exchanger, the effectiveness is given by:

$$
\varepsilon_{h x}=\frac{1-e^{-N T U\left(1-C_{r}\right)}}{1-C_{r} e^{-N T U\left(1-C_{r}\right)}}
$$

where $N T U=(U A)_{h x} / C_{\min }$ is the number of transfer units in which $U$ and $A$ are overall heat transfer coefficient and heat transfer area, respectively; the subscript $h x$ denotes heat exchanger; $C_{r}=C_{\min } / C_{\max }$ where $C_{\min }=(\dot{m} c)_{i}$ is the smaller heat capacity rate among two flows ( $i=$ internal or external flow), and $C_{\max }$ is the larger heat capacity rate between the two. In the current study, $C_{\min }=(\dot{m} c)_{f w}$ and $C_{\max }=(\dot{m} c)_{s w}$ in all cases. Consequently, seawater temperature at the SWHX condenser outlet is given by:

$$
T_{s w, o u t}=\varepsilon_{h x} C_{r}\left(T_{S W H X, f w, i n}-T_{s w, i n}\right)+T_{s w, i n}
$$

where the subscripts $f w, s w$, in, and out, refer to freshwater, seawater, inlet, and outlet, respectively, and $T_{S W H X, f w, i n}$ is the freshwater temperature at the SWHX hot side inlet. In all cases, $T_{s w, i n}$ is equal to the seawater temperature, $T_{s w}$.

Heat transfer rate between two fluid streams in element type 2 is calculated as follows:

$$
\dot{Q}_{c o n v, i}=(\dot{m} c)_{f w}\left(T_{S W H X, f w, i n}-T_{i}\right)+(\dot{m} c)_{s w}\left(T_{s w, i n}-T_{s w, o u t}\right)
$$

where the subscript $i$ refers to VE type under consideration, $(\dot{m} c)_{f w}$ and $(\dot{m} c)_{s w}$ are zonal freshwater and seawater heat capacity rates, respectively, $T_{i}$ the temperature of the element which is assumed to be equal to the exit temperature of freshwater, according to the assumption of uniform thermodynamic properties within the control volume. $T_{S W H X, f w, i n}$ is also the mixed freshwater temperature at the outlet of each thermal zone given by:

$$
T_{S W H X, f w, i n}=\frac{\sum_{j=1}^{n_{e q}} \dot{m}_{f w, j} T_{j}}{\dot{m}_{f w}}
$$

where $\dot{m}_{f w, j}$ is the freshwater mass flow rate coming from component $\mathrm{j}, T_{j}$ the temperature of component $j$ (assuming thermal equilibrium with the fluid 
temperature leaving the system), $\dot{m}_{f w}$ the zonal freshwater mass flow rate, and $n_{e q}$ the total number of components cooled by freshwater in the respective zone.

\subsection{Chilled water unit (CWU)}

Chilled water unit (CWU) is a vapor compression refrigeration system that rejects heat to seawater in the condenser [36. CWU extracts heat from freshwater before it is distributed back to freshwater-cooled (FWC) loads and air conditioning units (ACUs). One of the primary objectives of this work is to compute the CWU and ACU cooling capacities, $\dot{Q}_{C W U}$ and $\dot{Q}_{A C U}$, respectively, required by each thermal zone to maintain every corresponding equipment temperatures within their design limits. Therewith, $\dot{Q}_{C W U}$ is computed as follows:

$$
\dot{Q}_{C W U}=(\dot{m} c)_{f w}\left(T_{C W U, f w, o u t}-T_{S W H X, f w, o u t}\right)
$$

where $T_{S W H X, f w, o u t}$ is the freshwater temperature at the CWU evaporator inlet which is equivalent to freshwater temperature at the SWHX hot side outlet, and $T_{C W U, f w, \text { out }}$ is the desired freshwater temperature supplied to thermal loads. As a future work, it is of interest to implement a robust dynamic vapor compression model into vemESRDC in efforts to capture transient behavior of refrigerants and compressor power needed to satisfy the cooling requirements.

\subsection{Air conditioning unit (ACU)}

Air conditioning unit (ACU) is a vapor compression refrigeration system designed to cool air and unlike the CWU which uses seawater as its heat sink, the onboard ACU rejects heat to the freshwater supplied by CWU. The ACU cooling capacity $\dot{Q}_{A C U}$ is computed as:

$$
\dot{Q}_{A C U}=(\dot{m} c)_{a i r}\left(T_{A C U, a i r, o u t}-T_{A C U, a i r, i n}\right)
$$

where $(\dot{m} c)_{a i r}$ is the air heat capacity rate, $T_{A C U, \text { air,out }}$ is the desired supply air temperature and $T_{A C U, \text { air,in }}$ is the air temperature at the ACU evaporator inlet obtained from Eq. 20 for the AC loads. Presuming a given coefficient 
of performance $(\mathrm{COP})$, freshwater temperature at the $\mathrm{ACU}$ condenser outlet $T_{A C U, f w, o u t}$ is computed as follows:

$T_{A C U, f w, \text { out }}=T_{C W U, f w, \text { out }}-\frac{(\dot{m} c)_{a i r}}{(\dot{m} c)_{f w}}\left(T_{A C U, \text { air }, \text { out }}-T_{A C U, \text { air }, \text { in }}\right)\left(1+\frac{1}{C O P_{A C U}}\right)$

Freshwater leaves the condenser at higher temperature and it is mixed at the junction with freshwater from other freshwater-cooled (FWC) loads according to Eq. 20.

\subsection{Freshwater-cooled and seawater-cooled components}

The net heat transfer rate to the freshwater stream crossing any element $i$ of type 5 in the zone is calculated as follows:

$$
\dot{Q}_{c o n v, i}=\dot{m}_{f w, i} c_{f w}\left(T_{C W U, f w, o u t}-T_{i}\right)
$$

where $\dot{m}_{f w, i}$ is the fraction of freshwater mass flow rate through the corresponding VE $i$. Similarly, the net heat transfer rate through the seawater-cooled volume element $i$ of any element type 6 in the zone is calculated as follows:

$$
\dot{Q}_{c o n v, i}=\dot{m}_{s w, i} c_{s w}\left(T_{s w, i n}-T_{i}\right)
$$

where $\dot{m}_{s w, i}$ is the seawater mass flow rate fraction through the corresponding VE $i$. When two or more VEs are assigned to an equipment, for example, the given mass flow rate fraction is divided among the number of elements constituting the equipment.

\subsection{Air-conditioned components (AC)}

Mathematical formulation for air-conditioned (AC) loads of VE type 7 is similar to that of VE type 5 and 6 . Heat generated within the control volume representing the load is rejected to the air stream coming from the air conditioning unit (ACU). The net heat transfer rate through the air stream crossing any element of type 7 in the zone is calculated as follows:

$$
\dot{Q}_{c o n v, i}=\dot{m}_{a i r, i} c_{a i r}\left(T_{A C U, a i r, o u t}-T_{i}\right)
$$


where $\dot{m}_{a i r, i}$ is the air mass flow rate fraction through the corresponding element $i$, and $T_{i}$ is the temperature of the volume element $i$ which is assumed to be equal to the exiting air temperature..

\section{Case studies}

This section elaborates three case studies through which dynamic thermal response of the Notional Destroyer is examined using vemESRDC, as well as the notional data for three particular modes of ship operation: shore, cruise, and battle. Three features of ship thermal responses scrutinized throughout these analyses are: (1) cooling capacities required by the ship refrigeration system in each thermal zone to retain all its respective equipment temperatures within their design limits; and (2) temperature variations of freshwater, seawater, and major thermal loads with respect to partial ship cooling loss; and (3) the impacts of pre-cooling freshwater with a SWHX before directing it to the CWU. In addition, ship thermal responses were simulated under two extreme weather conditions by considering two fictitious mission locations, e.g., East Gulf of Mexico and Gulf of Alaska, with extremely different average ambient air and seawater temperatures. Subsequently, the required ship cooling capacities in each location were evaluated and compared.

\subsection{System design}

\subsubsection{Thermal loads}

This assessment considered a total of 54 notional thermal loads placed into four zones and their cooling strategies. The notional equipment (except for the vital loads) and environmental data (e.g., location, dimension, ambient conditions, etc.) for each operation mode under analysis were imported from Smart Ship System Design (S3D) environment [37. Position with respect to the ship origin, physical dimensions, and heat generation rate of each equipment in three operation modes are listed in Table 1. Auxiliary converters (CONV) and inverters (INV) for each respective weapon system and zone were also included in 
the simulation in an effort to depict actual ship compartments as accurately as possible. The assumed temperature limit for all shipboard components in the present analysis was $323.15 \mathrm{~K}\left(122^{\circ} \mathrm{F}\right)$.

\subsubsection{Thermal management system}

As shown in Figure 7 each zone is cooled by a single stand-alone freshwater system, air conditioning system, and SWHX. For the purposes of these test cases, the zones are not interconnected and there is no redundant equipment, i.e. only a single CWU, ACU and SWHX in each zone. This allows the determination of minimum sizing of such components without considering installed redundancy.

Plate and frame type seawater heat exchangers (SWHX) were assumed in all four zones with $U A$ of $61,991.8 \mathrm{~W} / \mathrm{K}$ [38. Desired freshwater and air temperatures at the $\mathrm{CWU}$ and $\mathrm{ACU}$ evaporator outlets, i.e., $T_{C W U, f w, o u t}$ and $T_{A C U, \text { air,out }}$, were $280 \mathrm{~K}\left(44^{\circ} \mathrm{F}\right)$ and a COP of 2.5 was assumed for all ACUs. For the freshwater and air circuits, the zonal freshwater and air mass flow rates were divided among the components cooled by each respective fluid within the zone. Consequently, corresponding mass flow rate fraction supplied to each individual $\mathrm{FWC}$ or $\mathrm{AC}$ component was determined according to the ratio of the component's heat generation rate to the zonal FWC or AC thermal load in the respective zone, which varied according to the operation mode.

The zonal freshwater mass flow rates were also evaluated as functions of the total zonal thermal load $\dot{Q}_{\text {load }}$ for each operation mode. The minimum allowed zonal mass flow rate required to maintain all equipment under the ceiling temperature was determined from a simple energy balance as follows:

$$
\dot{m}_{f w, z}=\frac{\dot{Q}_{l o a d, z}}{c_{f w}\left(T_{e q, \text { max }}-T_{C W U, f w, o u t}\right)}
$$

where $z$ stands for zone and $T_{e q, \max }$ for the equipment ceiling temperature. Noteworthy is that $\dot{Q}_{l o a d, z}$ is the sum of zonal FWC and AC thermal loads, owing to the fact that ACUs are cooled by the freshwater from CWUs. For each $\mathrm{CWU}$, an additional cooling capacity of $10 \mathrm{~kW}$ was added to the zonal cooling 
Table 1: Positions and dimensions of the components, and their heat generation rate in three modes of operation.

\begin{tabular}{|c|c|c|c|c|c|c|c|c|c|}
\hline \multirow{2}{*}{ omponent } & \multicolumn{3}{|c|}{ Position (m) } & \multicolumn{3}{|c|}{ Dimension $(\mathrm{m})$} & \multicolumn{3}{|c|}{ Heat Generation (MW) } \\
\hline & $\mathrm{x}$ & $\mathrm{y}$ & $\mathrm{z}$ & $\mathrm{dx}$ & dy & $\mathrm{dz}$ & Shore & Cruise & Battle \\
\hline CHILLER _Z1 & 27.85 & -3.05 & 4.45 & 6 & 2 & 2 & 0.00 & 0.00 & 0.00 \\
\hline NonVitalLoad_Z1 & 13.47 & 3.52 & 12.5 & 1 & 1 & 1 & 0.10 & 0.10 & 0.11 \\
\hline VitalLoad_Z1 & 8 & -0.5 & -0.5 & 2 & 1 & 1 & 1.00 & 1.00 & 1.05 \\
\hline CONV_RailGun_1_Z1 & 22.92 & 4.21 & 9.5 & 3 & 1 & 2 & 0.00 & 0.00 & 0.12 \\
\hline CONV_RailGun_2_Z1 & 17.04 & -2.59 & 4.2 & 3 & 1 & 2 & 0.00 & 0.00 & 0.00 \\
\hline Rail_Gun_Z1 & 18.89 & -3 & 13.5 & 3 & 6 & 4 & 0.00 & 0.00 & 2.80 \\
\hline HEATEXZ1 & 27.14 & 0.43 & 3.91 & 6 & 1 & 2 & 0.00 & 0.00 & 0.00 \\
\hline INV_1_Z1 & 30.56 & 4.95 & 9.5 & 4 & 1 & 2 & 0.19 & 0.19 & 0.47 \\
\hline INV_2_Z1 & 10.55 & -1.48 & 4.2 & 4 & 1 & 2 & 0.00 & 0.00 & 0.00 \\
\hline ACU_Z1 & 10 & -0.5 & 5 & 1 & 1 & 1 & 0.00 & 0.00 & 0.00 \\
\hline CHILLER _Z2 & 38.37 & 1.25 & 0 & 6 & 2 & 2 & 0.00 & 0.00 & 0.00 \\
\hline LM1600_stbd_Z2 & 48.25 & 2.15 & 4.38 & 12 & 2 & 3 & 0.03 & 0.03 & 0.03 \\
\hline LM2500_port_Z2 & 45.9 & -4.65 & 3.88 & 16 & 3 & 4 & 0.16 & 0.16 & 0.16 \\
\hline NonVitalLoad_Z2 & 42.2 & 3.52 & 8.5 & 1 & 1 & 1 & 0.40 & 0.40 & 0.14 \\
\hline VitalLoad_Z2 & 39.64 & 1.19 & 12.5 & 2 & 1 & 1 & 0.40 & 0.50 & 0.80 \\
\hline Stbd_prop_motor_Z & 61.53 & 2.5 & 4.5 & 7 & 3 & 3 & 0.00 & 0.14 & 1.03 \\
\hline RECT_port_Z2 & 56.6 & -4.12 & 7.7 & 4 & 1 & 2 & 0.76 & 0.76 & 0.76 \\
\hline RECT_stbd_Z2 & 58.36 & 2.3 & 9 & 2 & 1 & 2 & 0.00 & 0.00 & 0.38 \\
\hline INV_stbd_prop_Z2 & 62.07 & -1 & 4 & 6 & 2 & 2 & 0.00 & 0.00 & 0.00 \\
\hline CONV_Radar_1_Z2 & 42.5 & -4.5 & 2 & 3 & 1 & 2 & 0.00 & 0.06 & 0.15 \\
\hline CONV_Radar_2_Z2 & 50.94 & 5.32 & 12 & 3 & 1 & 2 & 0.00 & 0.00 & 0.00 \\
\hline RADAR_Z2 & 46 & -0.5 & 25.5 & 2 & 1 & 3 & 0.00 & 1.40 & 3.50 \\
\hline HEATEXZ2 & 38.23 & -1.52 & 4.01 & 6 & 1 & 2 & 0.00 & 0.00 & 0.00 \\
\hline INV_1_Z2 & 56.03 & 5.24 & 13 & 4 & 1 & 2 & 0.02 & 0.05 & 0.17 \\
\hline INV_2_Z2 & 38.19 & -4.22 & 3.69 & 1 & 1 & 1 & 0.00 & 0.00 & 0.00 \\
\hline ACU_Z2 & 40 & -0.5 & 5 & 1 & 1 & 1 & 0.00 & 0.00 & 0.00 \\
\hline CHILLER_Z3 & 70.61 & -0.52 & -0.27 & 6 & 2 & 2 & 0.00 & 0.00 & 0.00 \\
\hline LM1600_port_1_Z3 & 54 & -4.2 & -0.5 & 12 & 2 & 3 & 0.08 & 0.08 & 0.08 \\
\hline LM2500_port_2_Z3 & 85.78 & -5.1 & 4.5 & 16 & 3 & 4 & 0.16 & 0.16 & 0.16 \\
\hline LM2500_stbd_Z3 & 85.95 & 2.5 & 3.88 & 16 & 3 & 4 & 0.16 & 0.16 & 0.16 \\
\hline NonVitalLoad_Z3 & 102.54 & -3.91 & 14.5 & 1 & 1 & 1 & 0.40 & 0.40 & 0.14 \\
\hline VitalLoad_Z3 & 87.35 & -0.5 & 9.5 & 2 & 1 & 1 & 0.40 & 0.40 & 0.80 \\
\hline ADS_Z3 & 93.76 & -1.84 & 6.5 & 1 & 1 & 1 & 0.00 & 0.00 & 3.00 \\
\hline RECT_port_1_Z3 & 71 & -6.5 & 6 & 2 & 1 & 2 & 0.00 & 0.38 & 0.38 \\
\hline RECT_port_2_Z3 & 96.4 & -3.5 & 0 & 4 & 1 & 2 & 0.00 & 0.00 & 0.76 \\
\hline RECT_stbd_Z3 & 96 & 0.5 & 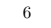 & 4 & 1 & 2 & 0.00 & 0.00 & 0.76 \\
\hline CONV_AD1_Z3 & 61.98 & 5.03 & 9.5 & 2 & 1 & 1 & 0.00 & 0.00 & 0.15 \\
\hline CONV_AD2_Z3 & 66.36 & -7.71 & 4.15 & 3 & 1 & 2 & 0.00 & 0.00 & 0.00 \\
\hline HEATEXZ3 & 70.42 & 3.21 & 4.01 & 6 & 1 & 2 & 0.00 & 0.00 & 0.00 \\
\hline INV_1_Z3 & 95.62 & 5.77 & 13 & 5 & 1 & 2 & 0.14 & 0.14 & 0.39 \\
\hline INV_2_Z3 & 62.22 & -4.36 & 7.7 & 4 & 1 & 2 & 0.00 & 0.00 & 0.00 \\
\hline ACU_Z3 & 80 & -0.5 & 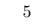 & 1 & 1 & 1 & 0.00 & 0.00 & 0.00 \\
\hline CHILLER_Z4 & 113.18 & 1.97 & 1 & 6 & 2 & 2 & 0.00 & 0.00 & 0.00 \\
\hline NonVitalLoad_Z & 123.84 & -3.91 & 10.5 & 1 & 1 & 1 & 0.10 & 0.10 & 0.07 \\
\hline VitalLoad_Z4 & 141.37 & 2.55 & 9 & 2 & 1 & 1 & 0.30 & 0.30 & 0.60 \\
\hline Port_prop_motor_Z4 & 102.08 & -5.5 & -0.5 & 7 & 3 & 3 & 0.00 & 0.14 & 1.03 \\
\hline INV_port_prop_Z4 & 103.2 & -0.92 & 1.3 & 6 & 2 & 2 & 0.00 & 0.00 & 0.00 \\
\hline CONV_Laser_1_Z4 & 132.42 & 4.31 & 4 & 3 & 1 & 2 & 0.00 & 0.00 & 0.15 \\
\hline CONV_Laser_2_Z4 & 123.58 & -2.86 & 4.2 & 2 & 1 & 2 & 0.00 & 0.00 & 0.00 \\
\hline LASER_Z4 & 153 & -1 & 9.02 & 2 & 2 & 2 & 0.00 & 0.00 & 3.75 \\
\hline HEATEXZ4 & 97 & -0.69 & 4.01 & 6 & 1 & 2 & 0.00 & 0.00 & 0.00 \\
\hline INV_1_Z4 & 136 & 5.01 & 9 & 4 & 1 & 2 & 0.01 & 0.03 & 0.14 \\
\hline INV_2_Z4 & 111.83 & -5.17 & 4.2 & 4 & 1 & 2 & 0.00 & 0.00 & 0.00 \\
\hline ACU_Z4 & 108 & -0.5 & 5 & 1 & 1 & 1 & 0.00 & 0.00 & 0.00 \\
\hline
\end{tabular}


capacity as the design margin. Zonal mass flow rates of air were determined in the same manner as for the freshwater, by replacing $\dot{Q}_{l o a d, z}$ in Eq. 27 with the zonal AC thermal load.

\subsection{Operational conditions}

In both scenarios analyzed in this work, it was assumed that the ship draft was $8 \mathrm{~m}$. Ambient air and seawater temperatures, $T_{\infty}$ and $T_{s w}$, changed according to the assumed mission locations, East Gulf of Mexico and Gulf of Alaska. In efforts to realistically simulate ship thermal responses under two contrasting weather conditions, average monthly ambient air and seawater temperatures for each location was obtained from National Oceanic and Atmospheric Administration [39; the selected months were May of 2015 for East Gulf of Mexico and December of 2015 for Gulf of Alaska. Subsequently, $T_{\infty}$ and $T_{s w}$ were 300.15 K $\left(80.6^{\circ} \mathrm{F}\right)$ and $293.15 \mathrm{~K}\left(68^{\circ} \mathrm{F}\right)$, respectively, for East Gulf of Mexico, and $279.15 \mathrm{~K}\left(42.8^{\circ} \mathrm{F}\right)$ and $278.65 \mathrm{~K}\left(41.9^{\circ} \mathrm{F}\right)$, respectively, for Gulf of Alaska. The seawater mass flow rate through SWHXs was retained constant at 42.8 $\mathrm{kg} / \mathrm{s}$ throughout the entire simulation. Further external and ship operational conditions imposed on all case studies are listed in Table 2

The three case studies consisted of simulating the ship in shore, cruise, battle, and cruise modes sequentially, yet with different scenarios. The time interval for each operation mode was arbitrarily selected to illustrate unexpected variations in system dynamics. Scenarios for the three case studies consisted of the following:

C. 1. The ship was simulated in shore, cruise, battle, and cruise mode for 1,800 $\mathrm{s}, 3,600 \mathrm{~s}, 3,600 \mathrm{~s}$, and 3,600 respectively, as one successful mission in East Gulf of Mexico.

C. 2. While the same simulation conditions as the first case study were imposed, the ship lost its cooling capabilities immediately after it engaged in a combat, starting with Zone 2, followed by Zone 1 and 3, and then Zone 4 . The ship eventually switched back to cruise mode and operated without 
Table 2: External and operational conditions.

\begin{tabular}{ll}
\hline Parameter & Value (unit) \\
\hline Average solar irradiance & $400 \mathrm{~W} / \mathrm{m}^{2}$ (top, north, and east) \\
& $0 \mathrm{~W} / \mathrm{m}^{2}$ (rest) \\
Frontal seawater speed & $1 \mathrm{~m} / \mathrm{s}$ (shore) \\
& $8.23 \mathrm{~m} / \mathrm{s}$ (cruise) \\
& $15.4 \mathrm{~m} / \mathrm{s}$ (battle) \\
& $3 \mathrm{~m} / \mathrm{s}$ (shore) \\
& $8.23 \mathrm{~m} / \mathrm{s}$ (cruise) \\
& $15.4 \mathrm{~m} / \mathrm{s}$ (battle) \\
& $300.15 \mathrm{~K}$ (ambient air, East Gulf of Mexico) \\
& $293.15 \mathrm{~K}$ (seawater, East Gulf of Mexico) \\
& $279.15 \mathrm{~K}$ (ambient air, Gulf of Alaska) \\
Temperature & $278.15 \mathrm{~K}$ (seawater, Gulf of Alaska) \\
\hline
\end{tabular}

cooling in all four zones. The time frame for each operation mode was the same as the first case study.

C. 3. The ship was simulated with the same simulation conditions as the first case study except in a different location, i.e., Gulf of Alaska, with contrasting weather conditions. Ambient air and seawater temperatures were altered accordingly as described in Section 5.2 .

The case studies consisted of several simulations that solved for the transient solution in each ship operation mode. For every simulation run, except for the first ones, the previous solution was imposed as an initial condition to the following simulation. Similarly, ambient conditions and equipment heat generation rates were updated accordingly for each operation mode. All simulations were performed on a computer with the following technical specifications: Intel Core i7-4980HQ 2.8 GHz, 16 GB RAM, UNIX-based system. The solutions were recorded at every 10 real-time seconds. 


\section{Results and discussion}

The independent mesh according to Eq. 1 1 had a total of 24,463 VEs, which was obtained in 149.8 central processing unit (CPU) seconds. Table 3 lists the dimensions and number of VEs in each spatial direction, and the independent mesh of Notional Destroyer is depicted in Figure 4. Throughout the discussion, all mass flow rates and cooling capacities are listed in a sequential order of zones, i.e., Zone 1, 2, 3, and 4, unless stated otherwise.

\begin{tabular}{lcc} 
Table 3: Notional ship dimensions and the number of discretized elements. \\
\hline Direction & Length $(\mathrm{m})$ & Number of VEs \\
\hline Bow to stern & 176 & 40 \\
Port to starboard & 22.6 & 25 \\
Keel to superstructure top & 29.7 & 55 \\
\hline
\end{tabular}

Appropriate zonal air and freshwater mass flow rates obtained from Eq. 27 for each operation mode, with a $10 \mathrm{~kW}$ design margin, are listed in Table 4 . AC loads were independent from zonal freshwater mass flow rates since air conditioning unit (ACU) was designed to cool down the air to $280 \mathrm{~K}\left(44^{\circ} \mathrm{F}\right)$ regardless of the freshwater mass flow rate. However, $T_{A C U, f w \text {, out }}$ increased as a function of $T_{A C U, a i r, i n}$ as noted in Eq. 23 vemESRDC was programmed to display an error when the temperature of freshwater or seawater at any part of the ship exceeded the nominal boiling temperature, i.e., $212^{\circ} \mathrm{F}$, to avoid any phase change which is not accounted for by the model. Likewise, warning was given when an equipment exceeded its ceiling temperature.

\subsection{Case Study 1}

CPU time required to simulate the ship thermal responses for 11,830 realtime seconds (time at which steady state was attained) in the first case study was $187.5 \mathrm{~s}$. Results of the first case study are depicted in Figure 8-12, where the operation mode switch is indicated with a dash-dot vertical line and the predefined equipment ceiling temperature with a dotted horizontal line. Note 
Table 4: Appropriate zonal air and freshwater flow rates for each operation mode, obtained from Eq. 27]with a $10 \mathrm{~kW}$ design margin.

\begin{tabular}{lcccc}
\hline \multirow{2}{*}{ Operation modes } & \multicolumn{5}{c}{ Zonal mass flow rate $(\mathrm{kg} / \mathrm{s})$} \\
& Zone 1 & Zone 2 & Zone 3 & Zone 4 \\
\hline Air & & & & \\
\hline Shore & 6.81 & 10.0 & 12.8 & 2.83 \\
Cruise & 6.81 & 10.6 & 12.8 & 3.14 \\
Battle & 16.4 & 7.19 & 15.9 & 8.47 \\
\hline Freshwater & & & & \\
\hline Shore & 7.15 & 9.84 & 7.45 & 2.33 \\
Cruise & 7.15 & 19.4 & 9.52 & 3.17 \\
Battle & 25.2 & 39.3 & 37.5 & 31.7 \\
\hline
\end{tabular}

that only particular thermal loads with high heat generation rates, such as pulse, vital, and non-vital loads, are scrutinized in the first and second case studies.

According to Figure 8, peak CWU refrigeration rate in all zones is found in battle mode at the rates of 3.28 MW, 5.72 MW, 5.61 MW, and 4.55 MW. In contrast to CWU, ACU refrigeration demands in battle mode are markedly lower since most of large thermal loads are cooled by freshwater, including ACU itself. Peak CWU refrigeration rates in all zones indicate that multiple CWUs are required, since the anticipated capacity of a shipboard CWU is between 200-425 tons [8, 40]. 

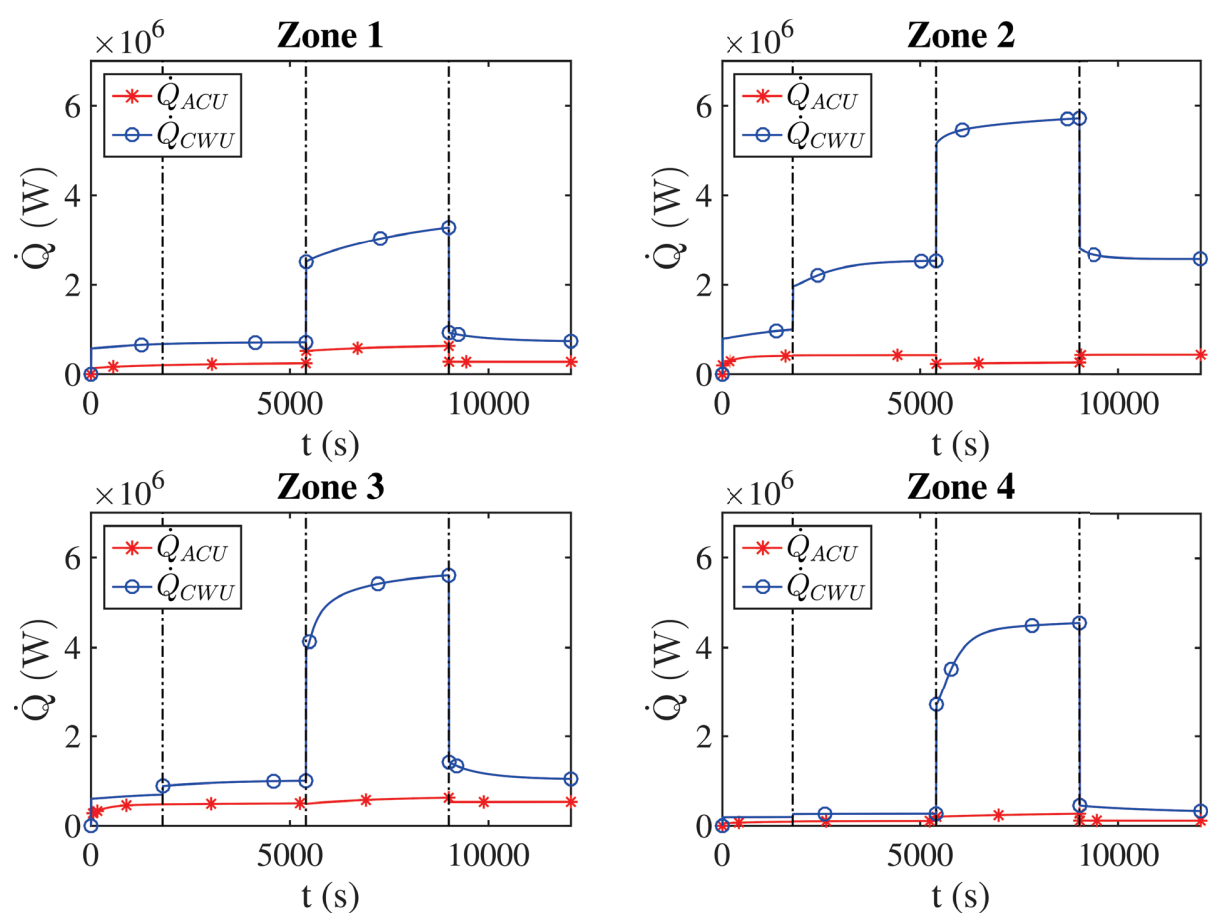

Figure 8: First case study: CWU and ACU refrigeration rate variations in the four zones in shore, cruise, battle, and cruise modes; $T_{C W U, \text { fw, out }}=T_{A C U, \text { air }, \text { out }}=280 \mathrm{~K}, T_{\infty}=$ $300.15 \mathrm{~K}$, and $T_{s w}=293.15 \mathrm{~K}$.

In this work, the freshwater temperature is dictated by the maximum temperature of the components to be cooled, assuming the CWU can accommodate any entering temperature. This high freshwater temperature provides a situation in which a direct seawater heat exchanger is effective. Figure 9 shows freshwater temperature variations at the SWHX hot side inlet $\left(T_{S W H X, f w, i n}\right)$ and outlet $\left(T_{S W H X, f w, o u t}\right)$ as well as seawater temperature at the SWHX cold side outlet $\left(T_{s w, o u t}\right)$.

The sudden drop in freshwater temperatures in Figure 9, after the ship switches to battle mode, owes to the way through which mass flow rate fractions have been determined. According to Eq. 27, zonal mass flow rates and their fraction supplied to each thermal load are determined based on the zonal and 
component heat generation rates, as well as the equipment ceiling temperature, $T_{e q, \max }$. In other words, loads with higher heat generation rates are subject to higher freshwater mass flow rates. In the ship, there exist several components that do not operate until battle mode as listed in Table 1 (e.g., converters, laser, railgun, etc.), whose thermal inertia and heat generation rates are high. Hence these loads remain at low temperature even after the ship switches to battle mode, with high freshwater mass flow rate across them. As a result, freshwater temperature at the equipment outlet is low and thus, sudden temperature drops are observed as in Figure 9. Thereafter, freshwater temperature increases along the load temperature, eventually up to $T_{e q, \max }$. Same is the case with air-cooled components.

The practicality of installing SWHXs to pre-cool freshwater before CWUs is demonstrated in the same figure, which shows significant decrease in freshwater temperature at the SWHX outlet compared to its inlet. As a result, the power required by the CWU can be minimized which leads to fuel savings. Moreover, required CWU capacities in Figure 8 can be reduced even further by installing larger SWHXs. It is of interest, as a future work, to study the effects on overall efficiency under a range of operating scenarios and ambient seawater temperatures, of various combinations of seawater, freshwater, and chilled water cooling using vemESRDC. 

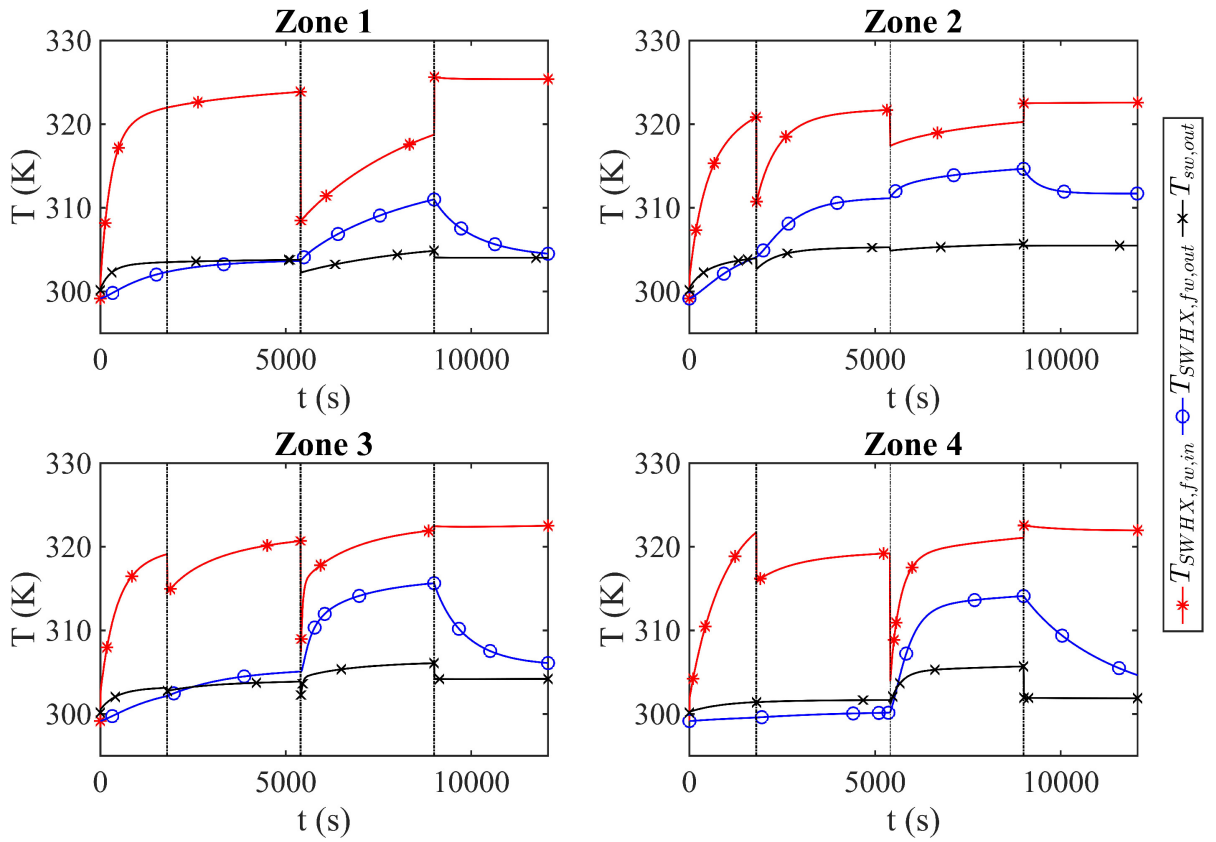

Figure 9: First case study: variations in the freshwater temperatures at the SWHX inlet and outlet and seawater temperature at the SWHX seaside outlet in shore, cruise, battle, and cruise modes; $T_{C W U, f w, \text { out }}=T_{A C U, \text { air }, \text { out }}=280 \mathrm{~K}, T_{\infty}=300.15 \mathrm{~K}$, and $T_{s w}=293.15 \mathrm{~K}$.

Figure 10 exhibits temperature variations of the pulse loads and their converters. ADS, laser, and radar attain peak temperatures near their celing temperature, $323.15 \mathrm{~K}\left(122^{\circ} \mathrm{F}\right)$, and these loads experience drastic temperature increase relative to the railgun owing to their smaller thermal inertia and higher heat generation rates. The railgun, although at a higher power level, has a lower cycle time and thus a lower average heat to be dissipated. Noteworthy is the thermal behavior of the ADS, laser, and railgun after battle, when these loads are turned off (no heat generation and dedicated cooling); Figure 10 features gradual temperature drops in these loads by natural convection only. Such an observation provides a valuable insight into the pulse load cooling strategy: full cooling to support steady state of the pulse loads is not needed immediately after each battle (or service). Instead, these loads can be allowed to decrease 
in temperature over time by natural convection or with minimum cooling, then cooled back down to initial temperature before their next service. Consequently, operational parameters such as the optimal cool-down time for pulse loads can be obtained using vemESRDC and not from a quasi-static analysis.
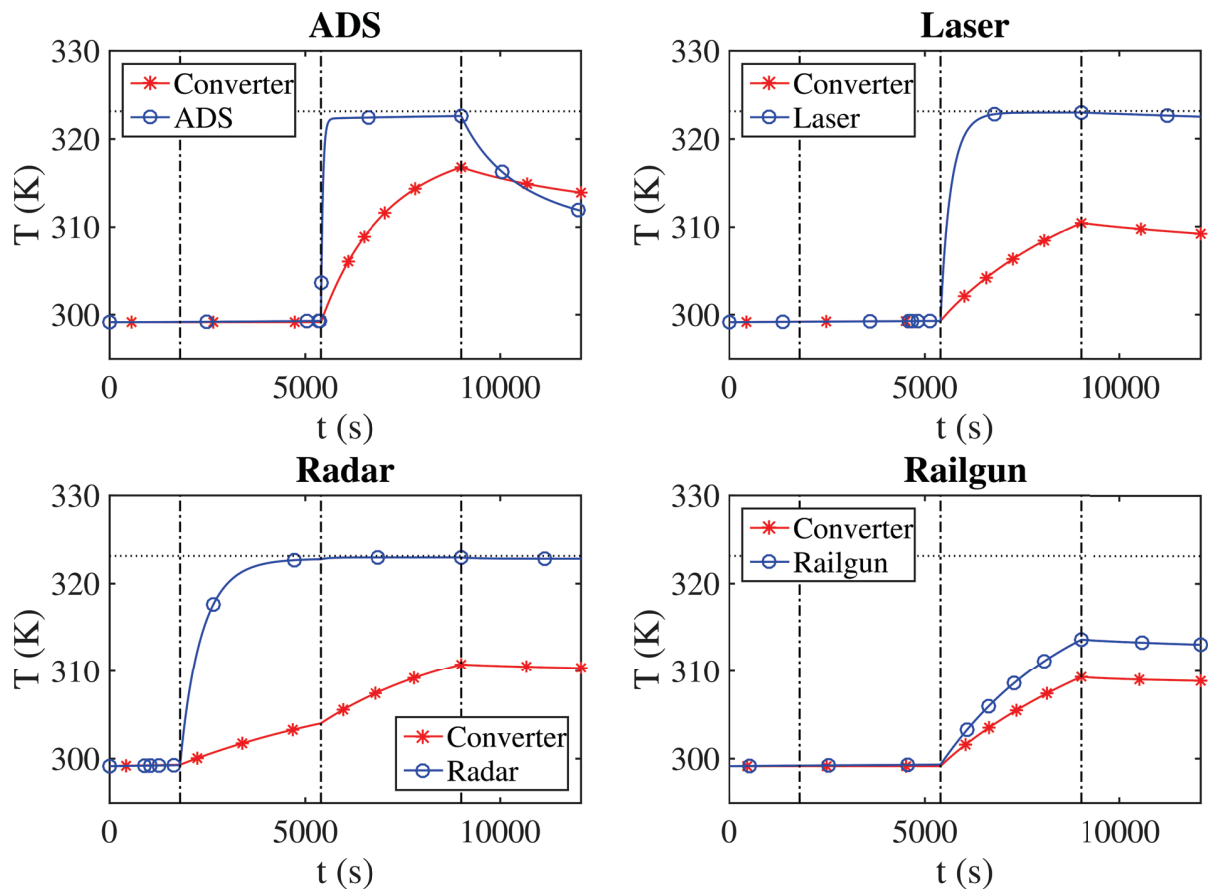

Figure 10: First case study: pulse load temperature variations in shore, cruise, battle, and cruise modes; $T_{C W U, f w, \text { out }}=T_{A C U, \text { air }, \text { out }}=280 \mathrm{~K}, T_{\infty}=300.15 \mathrm{~K}$, and $T_{s w}=293.15 \mathrm{~K}$.

Air and freshwater temperatures in ACUs are displayed in Figure 11. In the figure, $T_{A C U, \text { air,in }}$ refers to the temperature of the air returning from the air circuit after cooling $\mathrm{AC}$ loads while $T_{A C U, f w, \text { out }}$ stands for the freshwater temperature at the ACU condenser outlet, which eventually flows back to CWU. Air and freshwater temperature curves in Figure 11 exhibit nearly identical trends, i.e., linearly proportional, owing to the assumptions made in Section 4.3 for deriving Eq. 23. Figure 12 depicts the temperature variations of vital and non-vital loads, which remain near their ceiling temperature throughout the 
simulation period. Note that vital and non-vital loads are FWC and AC loads, respectively.
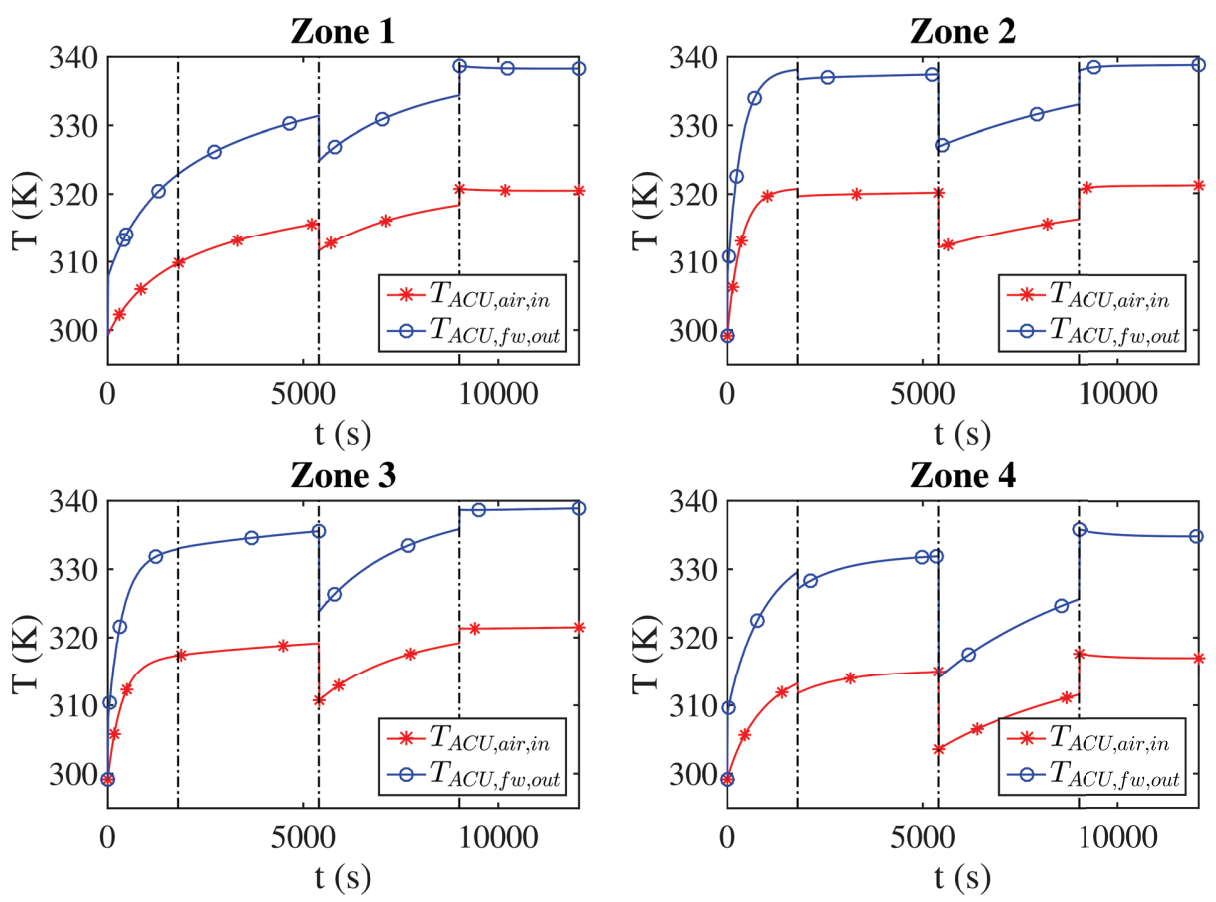

Figure 11: First case study: air and freshwater temperature variations in ACUs in shore, cruise, battle, and cruise modes; $T_{C W U, f w, \text { out }}=T_{A C U, \text { air }, \text { out }}=280 \mathrm{~K}, T_{\infty}=300.15 \mathrm{~K}$, and $T_{s w}=293.15 \mathrm{~K}$. 

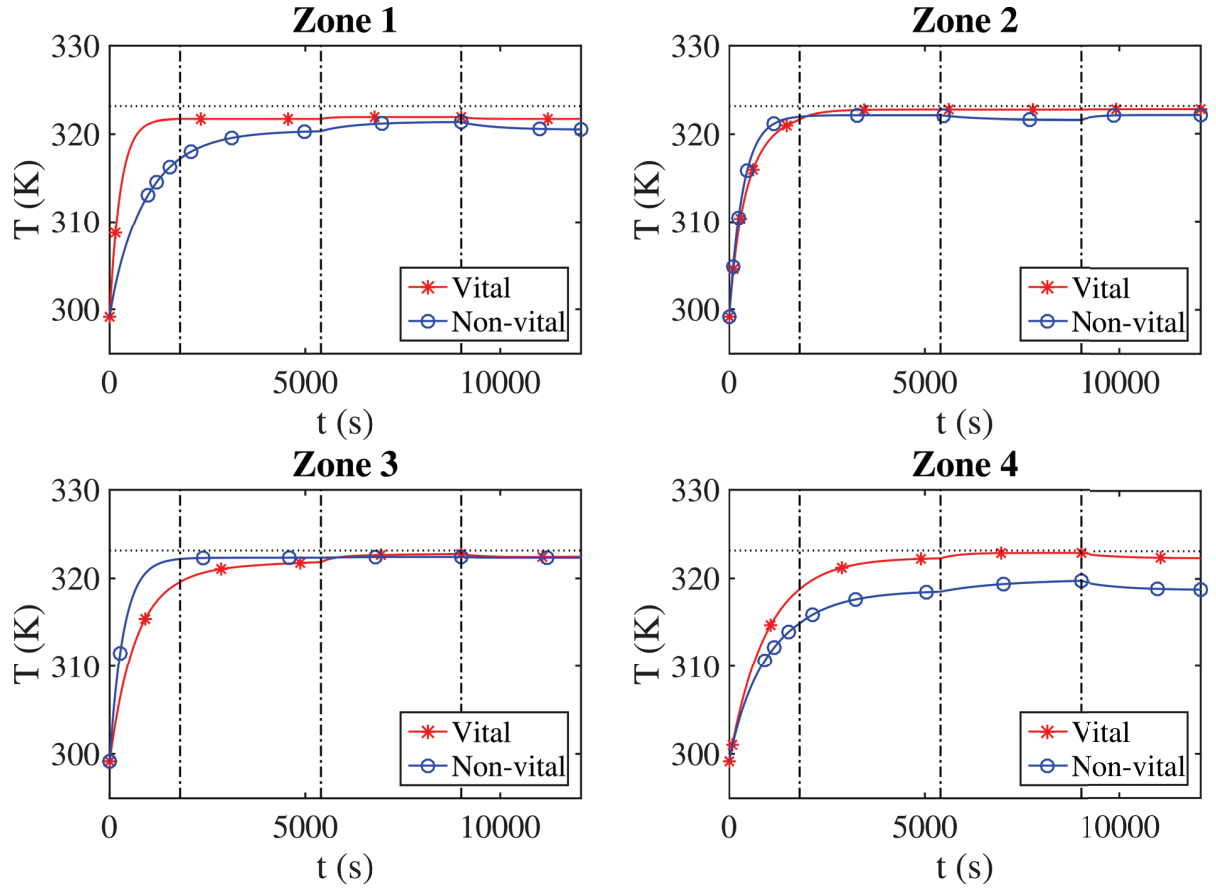

Figure 12: First case study: vital load temperature variations in shore, cruise, battle, and cruise modes; $T_{C W U, f w, \text { out }}=T_{A C U, \text { air }, \text { out }}=280 \mathrm{~K}, T_{\infty}=300.15 \mathrm{~K}$, and $T_{s w}=293.15 \mathrm{~K}$.

The maximum ship temperature observed in the first case study was $337.6 \mathrm{~K}$, which was the temperature of the air adjacent to the north ship wall subjected to direct solar irradiance.

\subsection{Case study 2}

Results of the second case study were obtained in 221.1 CPU seconds, and they are depicted in Figure 13 17. Operation mode switch and the time at which partial ship cooling loss occurred in each zone are indicated with solid and dashdot vertical lines, respectively. Figure 13 shows CWU and ACU refrigeration rates in the four zones with respect to the operation modes, and sudden drops in the curves also indicate the time at which partial loss of cooling occurred. 

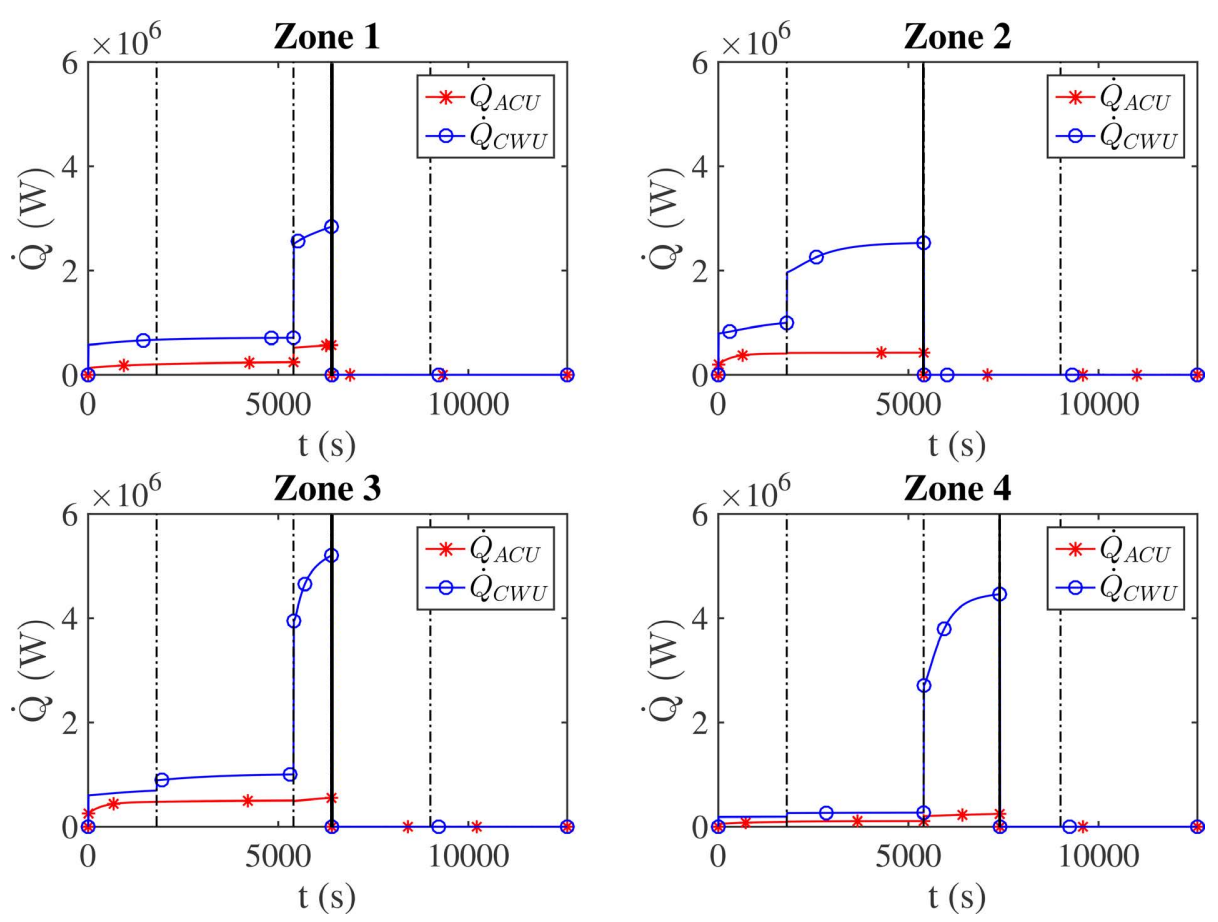

Figure 13: Second case study: CWU and ACU refrigeration rate variations subject to partial loss of cooling in the four zones in battle mode; $T_{C W U, f w, \text { out }}=T_{A C U, \text { air }, \text { out }}=280 \mathrm{~K}$, $T_{\infty}=300.15 \mathrm{~K}$, and $T_{s w}=293.15 \mathrm{~K}$.

Figure 14 features freshwater and seawater temperature variations entailed to partial cooling loss, in which the freshwater temperature exceeds its nominal boiling temperature, $212^{\circ} \mathrm{F}$, indicated by dotted horizontal lines. In other words, sudden loss of cooling may lead to detrimental outcomes not only for the loads, but also for the pipe network due to phase change before entering SWHXs. Similarly, air and freshwater in ACUs attain extremely high temperatures as shown in Figure 15, certainly resulting in undesirable system failures. 

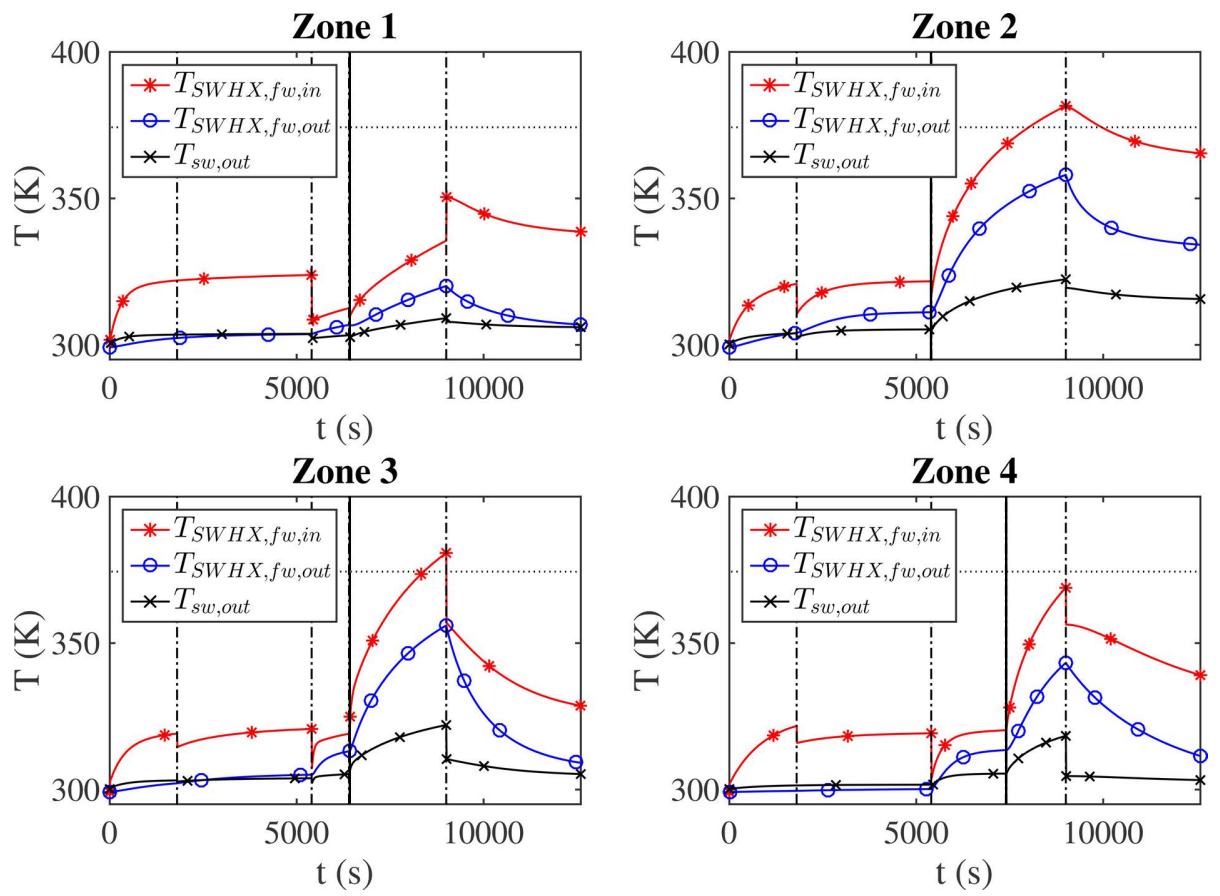

Figure 14: Second case study: variations in the freshwater temperatures at the SWHX inlet and outlet and seawater temperature at the SWHX seaside outlet subject to partial loss of cooling in battle mode; $T_{C W U, \text { fw, out }}=T_{A C U, \text { air }, \text { out }}=280 \mathrm{~K}, T_{\infty}=300.15 \mathrm{~K}$, and $T_{s w}=293.15 \mathrm{~K}$. 
Zone 1

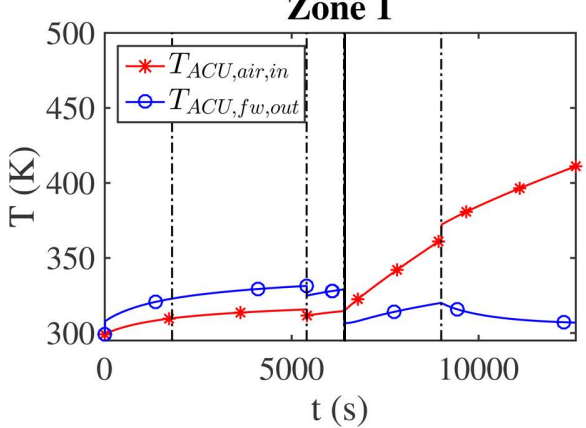

Zone 3

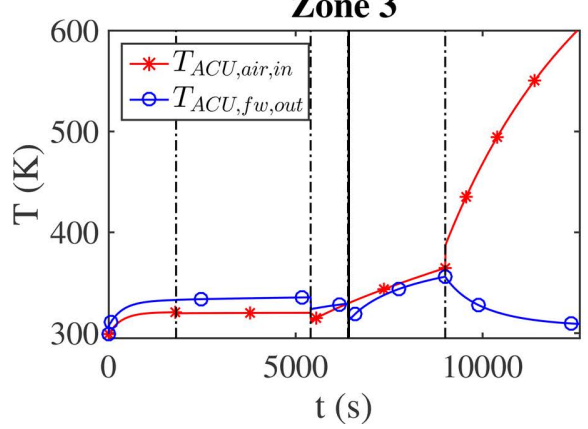

Zone 2

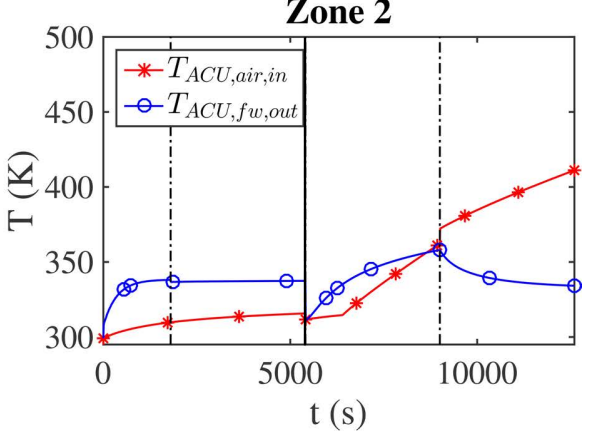

Zone 4

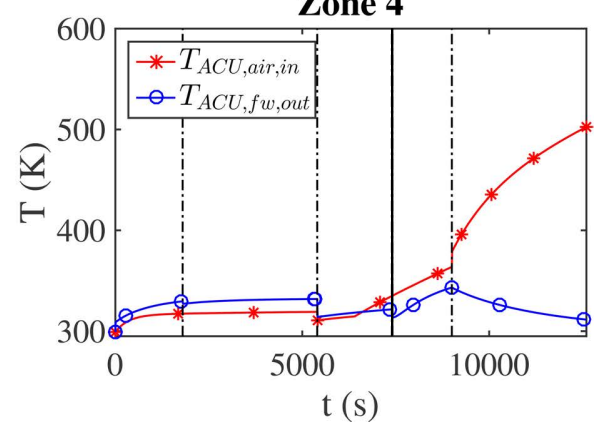

Figure 15: Second case study: air and freshwater temperature variations in ACUs subject to partial loss of cooling in battle mode; $T_{C W U, f w, \text { out }}=T_{A C U, \text { air }, \text { out }}=280 \mathrm{~K}, T_{\infty}=300.15 \mathrm{~K}$, and $T_{s w}=293.15 \mathrm{~K}$.

Figure 16 and 17 depicts the temperature variation of pulse, vital, and nonvital loads, where the curves show the same qualitative trends as those in the first case study until the ship loses its cooling capabilities. After the cooling loss, most of loads shown in the figures exhibit temperatures well above their design limits, indicated by dotted horizontal lines. Drastic temperature rise in large thermal loads due to sudden cooling loss can be mitigated by installing dedicated emergency cooling networks or by interconnecting the cooling network between zones. In practice, all-electric ships are anticipated to house two or more CWUs in each thermal zone with an interconnected cooling network between zones. Hence in case of partial cooling loss, remaining serviceable chillers can provide some respite for thermal loads and function as emergency cooling 
systems. Future work may include a multiple interconnected cooling systems, and investigate their performance and temperature variations of the loads subject to partial loss of cooling.
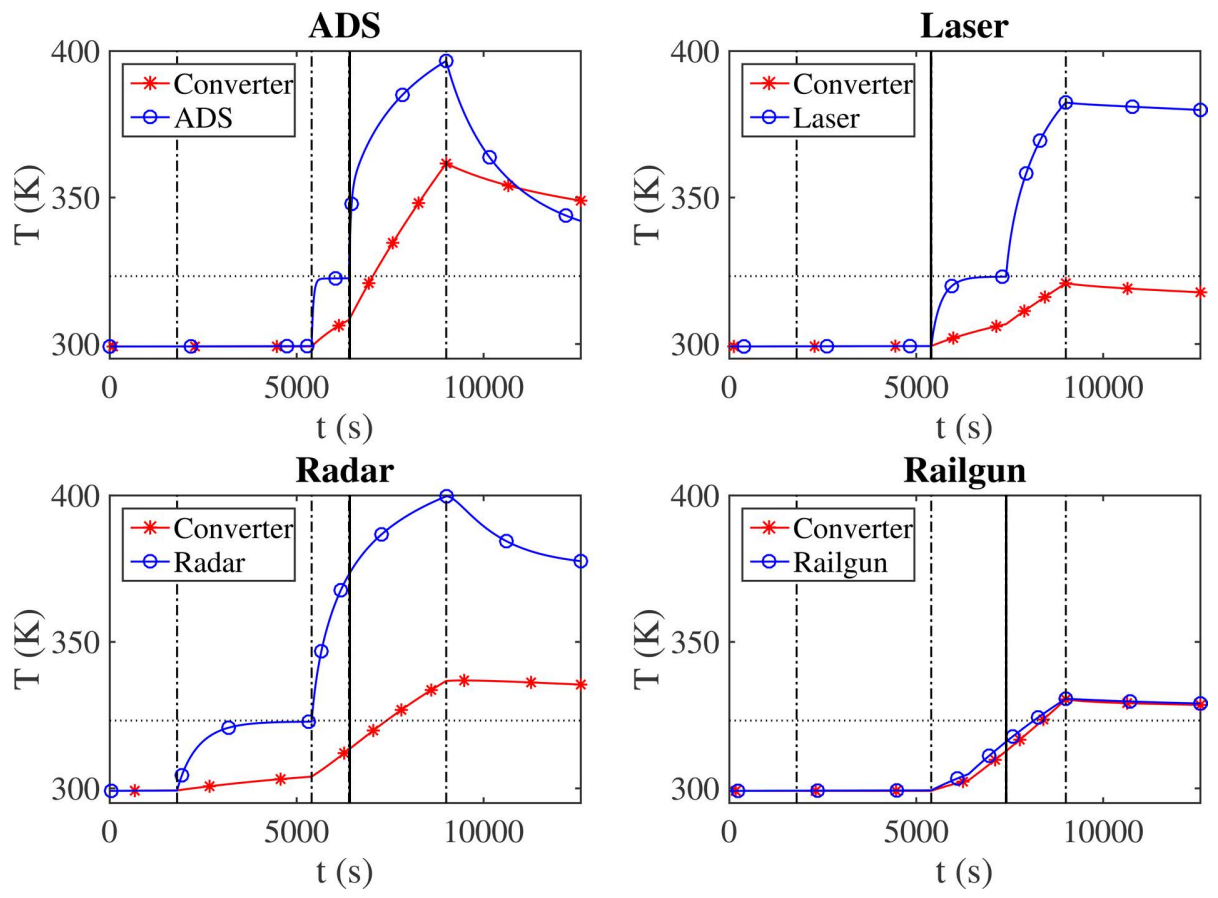

Figure 16: Second case study: pulse load temperature variations subject to partial loss of cooling in battle mode; $T_{C W U, f w, \text { out }}=T_{A C U, \text { air }, \text { out }}=280 \mathrm{~K}, T_{\infty}=300.15 \mathrm{~K}$, and $T_{s w}=$ $293.15 K$. 
Zone 1

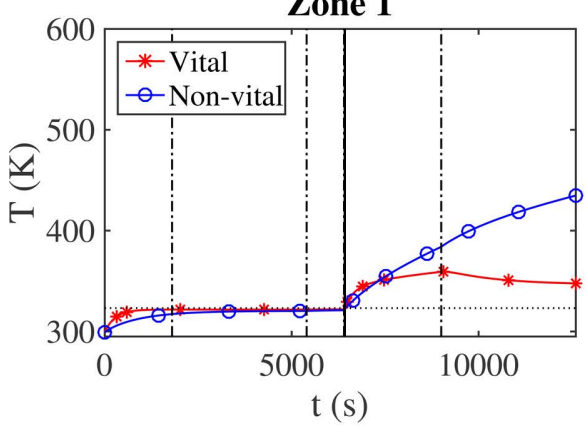

Zone 3

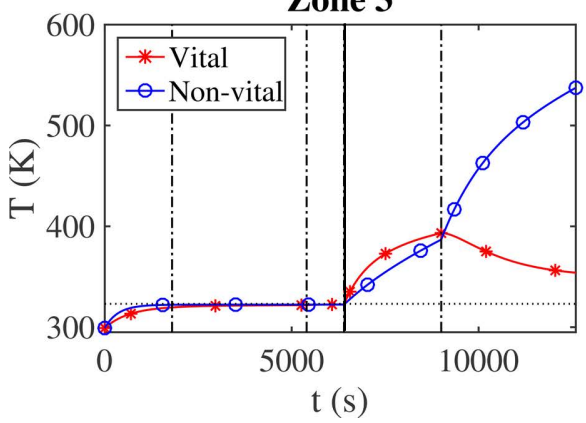

Zone 2

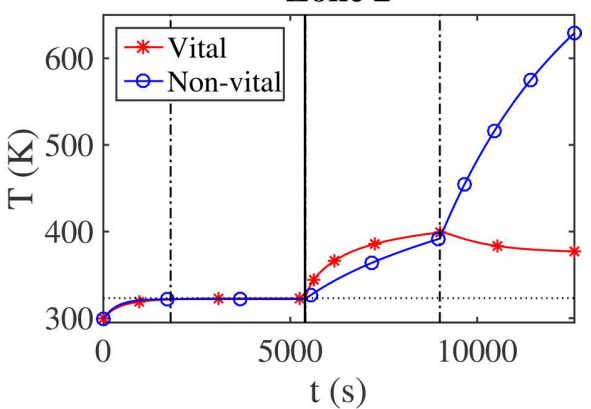

Zone 4

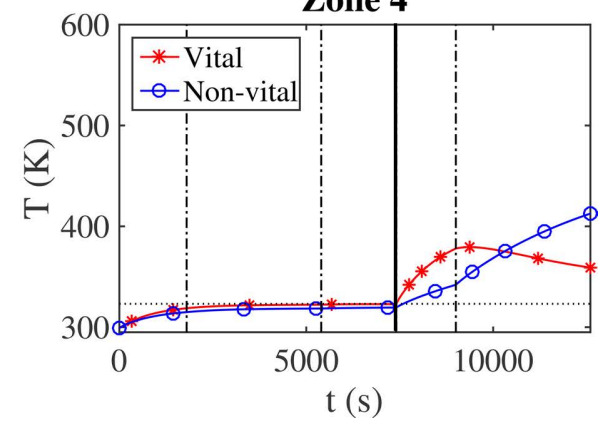

Figure 17: Second case study: vital load temperature variations subject to partial loss of cooling in battle mode; $T_{C W U, f w, \text { out }}=T_{A C U, \text { air }, \text { out }}=280 \mathrm{~K}, T_{\infty}=300.15 \mathrm{~K}$, and $T_{s w}=$ $293.15 K$.

\subsection{Case study 3}

The third case study focused on analyzing the change in the required cooling capacity under different weather conditions. As described in Section 5.2, third case study consisted of simulating the ship in Gulf of Alaska, with significantly lower air and seawater temperatures than East Gulf of Mexico considered in the first and second case studies. Required cooling capacities as well as freshwater and seawater temperature variations are depicted in Figure 18 and 19. 

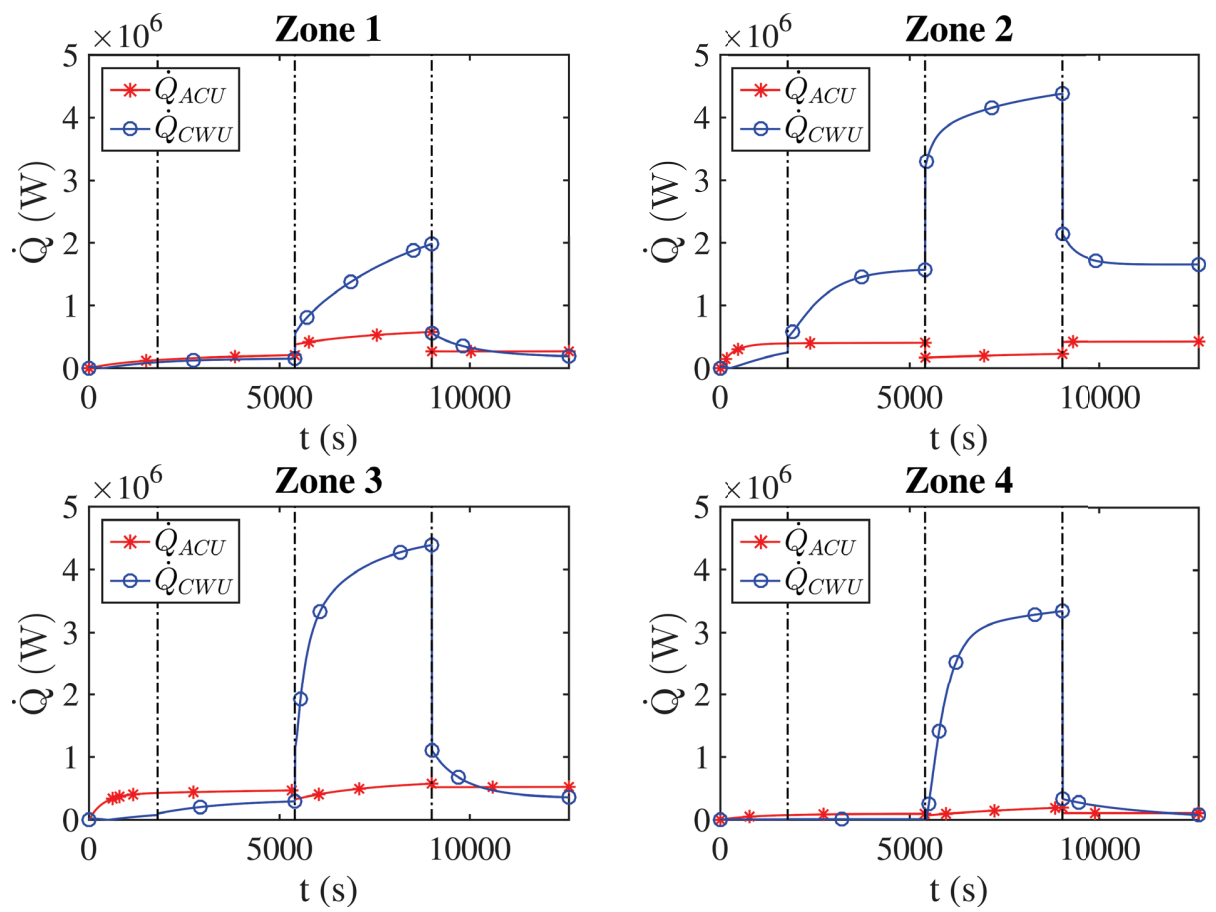

Figure 18: Third case study: CWU and ACU refrigeration rate variations in shore, cruise, battle, and cruise modes in Gulf of Alaska; $T_{C W U, f w, \text { out }}=T_{A C U, \text { air }, \text { out }}=280 \mathrm{~K}, T_{\infty}=$ $279.15 \mathrm{~K}$, and $T_{s w}=278.15 \mathrm{~K}$. 

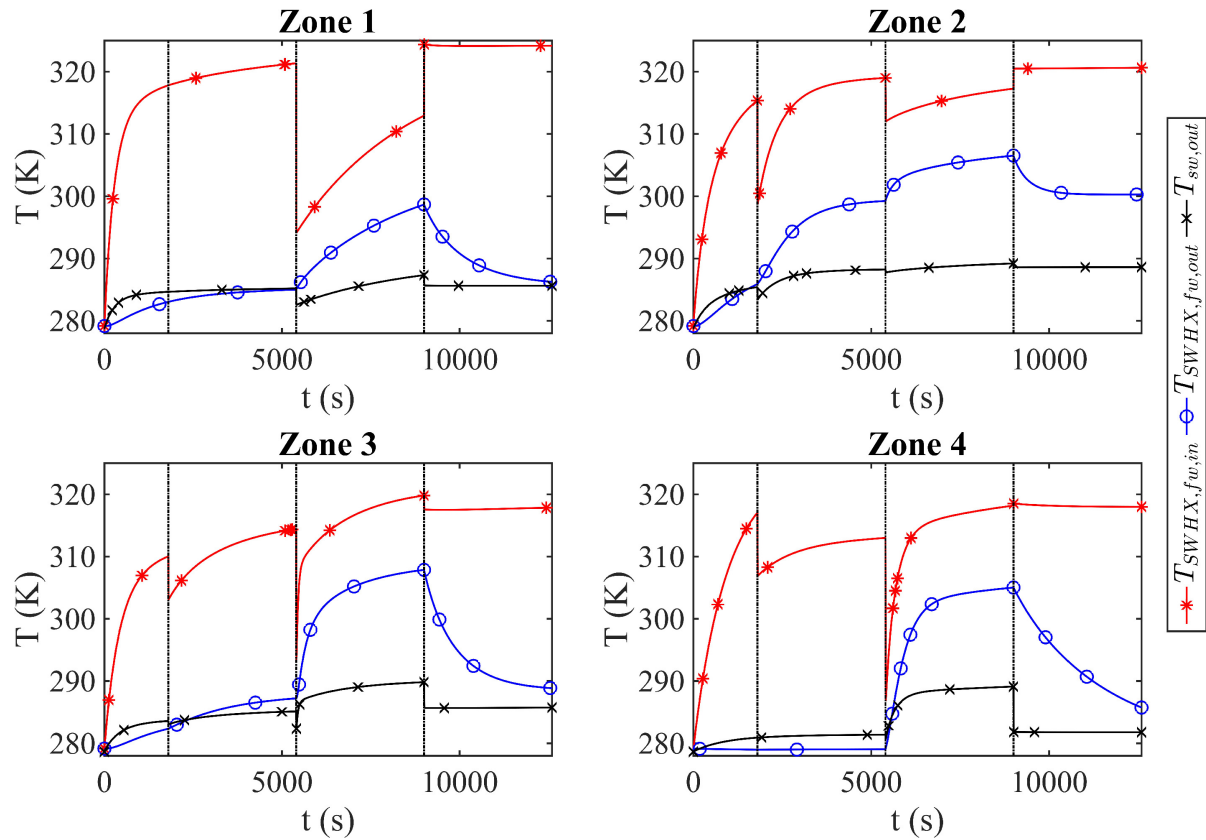

Figure 19: Third case study: variations in the freshwater temperatures at the SWHX inlet and outlet and seawater temperature at the SWHX seaside outlet in shore, cruise, battle, and cruise modes in Gulf of Alaska; $T_{C W U, f w, \text { out }}=T_{A C U, \text { air }, \text { out }}=280 \mathrm{~K}, T_{\infty}=279.15 \mathrm{~K}$, and $T_{s w}=278.15 \mathrm{~K}$.

Noteworthy is the reduction in the overall required CWU and ACU cooling capacities as well as the freshwater temperature in Gulf of Alaska. Similar to the results in Figure 8, peak CWU refrigeration rate in all zones is found in battle mode; however, at remarkably lower rates of $1.98 \mathrm{MW}, 4.38 \mathrm{MW}, 4.39$ MW, and 3.34 MW, which are 1.26 MW lower in average than those required in East Gulf of Mexico. Such a reduction in cooling capacity demand is attributed to SWHXs present to pre-cool the freshwater before chillers. Lower seawater temperature increases the heat rejection rate in SWHXs and therefore, lower freshwater temperature can be attained. The results in Figure 8 and 9 verify the assets of installing SWHXs for pre-cooling purposes, and it is clear that the performance of these heat exchangers increases with a decrease in seawater 
temperature.

The maximum ship temperature in the third case study was $328.2 \mathrm{~K}$, which was observed near the radar. The external ship temperature distribution after battle in Gulf of Alaska is shown in Figure 20, in which the temperature variation due to ship draft, solar irradiance, and the presence of ship equipment, are evident.

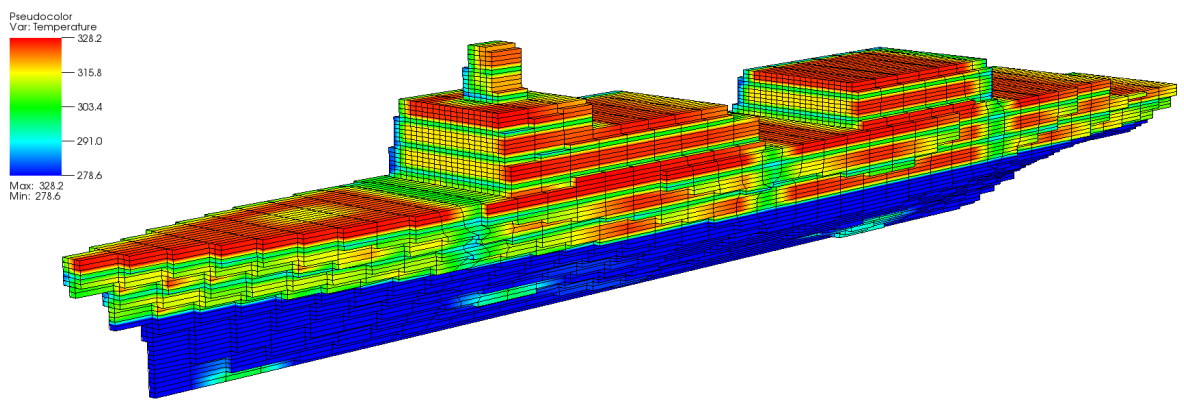

Figure 20: External ship temperature distribution after battle in Gulf of Alaska.

\section{Conclusion}

The paper presents the mathematical formulation and demonstration of vemESRDC for simulating dynamic ship thermal responses characterized by intricate thermal interactions within a complex ship structure. Both the capability and assets of vemESRDC, as a practical ship thermal management tool, have been demonstrated through three case studies in which transient thermal responses of an all-electric ship to different ship operation modes, weather conditions, and partial cooling loss have been investigated. For the notional allelectric ship conceived and assessed in this work, the results imply the following: (1) vemESRDC is able to capture dynamic thermal interactions between shipboard equipment and their respective surroundings as well as cooling systems, e.g., the tool provides practical insights into pulse load cooling strategy and different solutions are obtained with distinct weather conditions (ambient air and seawater temperatures); (2) multiple interconnected cooling systems are 
vital to avert detrimental consequences within all-electric ships subject to sudden partial cooling losses; and (3) seawater heat exchangers markedly reduce the cooling capacity required by chillers, which leads to fuel savings. In addition to the case studies performed in this work, vemESRDC can be employed to conduct diverse studies based on which concrete ship thermal management strategies can be formulated in early design stages.

\section{Acknowledgment}

This work was supported through the Office of Naval Research (ONR) grant N00014-14-1-0198. Any opinions, findings and conclusions or recommendations are those of the authors and do not necessarily reflect the views of the Office of Naval Research. The authors would like to thank David Kopriva at FSU Department of Mathematics for his suggestions on the implementation of numerical methods.

\section{References}

[1] N. H. Doerry, J. C. Davis, Integrated power system for marine applications, Naval Engineers Journal 106 (3) (1994) 77-90.

[2] M. Zerby, Thermal management for the electric warship, in: Proceedings of the 2006 Electric Machine Technology Symposium, ASNE, 2006.

[3] T. W. Webb, T. M. Kiehne, S. T. Haag, System-level thermal management of pulsed loads on an all-electric ship, Magnetics, IEEE Transactions on 43 (1) (2007) 469-473.

[4] A. N. Smith, B. T. McGlasson, J. S. Bernardes, Heat generation during the firing of a capacitor-based railgun system, Magnetics, IEEE Transactions on 43 (1) (2007) 190-193.

[5] J. Amy, Load analysis 2007 for esrdc3 rev2. xls, Electric Ship Research and Development Consortium. 
[6] T. Chiocchio, R. Schrattenecker, S. Yang, J. Ordonez, M. Steurer, Developing a validated real-time system-level thermal simulation for future all-electric ships, in: Electric Ship Technologies Symposium (ESTS), 2013 IEEE, IEEE, 2013, pp. 76-81.

[7] R. Fang, W. Jiang, J. Khan, R. Dougal, System-level thermal modeling and co-simulation with hybrid power system for future all electric ship, in: Electric Ship Technologies Symposium, 2009. ESTS 2009. IEEE, IEEE, 2009, pp. 547-553.

[8] R. Fang, W. Jiang, J. Khan, R. Dougal, Thermal modeling and simulation of the chilled water system for future all electric ship, in: Electric Ship Technologies Symposium (ESTS), 2011 IEEE, IEEE, 2011, pp. 265-271.

[9] P. T. Hewlett, T. M. Kiehne, Dynamic simulation of ship-system thermal load management, in: Automation Science and Engineering (CASE), 2010 IEEE Conference on, IEEE, 2010, pp. 734-741.

[10] P. B. Backlund, C. C. Seepersad, T. M. Kiehne, A system-level design framework for all-electric ship thermal systems, in: Proceedings of the 2012 Electric Machine Technology Symposium, ASNE, 2012.

[11] A. B. Sanfiorenzo, Cooling system design tool for rapid development and analysis of chilled water systems aboard us navy surface ships, Master's thesis, Cambridge, Massachussetts, Massachussetts Institute of Technology (2013).

[12] E. Dilay, J. V. C. Vargas, J. A. Souza, J. C. Ordonez, S. Yang, A. B. Mariano, A volume element model (vem) for energy systems engineering, International Journal of Energy Research 39 (1) (2015) 46-74.

[13] S. Yang, J. V. Vargas, T. Nunes, J. C. Ordonez, Development and implementation of a dynamic vapor compression refrigeration model into vemesrdc ship thermal management tool, in: Electric Ship Technologies Symposium (ESTS), 2015 IEEE, IEEE, 2015, pp. 123-128. 
[14] S. Yang, J. C. Ordonez, J. V. Vargas, H. Babaee, J. Chalfant, C. Chryssostomidis, Comprehensive system-level thermal modeling of all-electric ships: Integration of smcs and vemesrdc, in: Electric Ship Technologies Symposium (ESTS), 2015 IEEE, IEEE, 2015, pp. 251-255.

[15] E. Dilay, J. Vargas, J. Ordonez, S. Yang, R. Schrattenecker, M. Coleman, T. Chiocchio, J. Chalfant, C. Chryssostomidis, The experimental validation of a transient power electronic building block (pebb) mathematical model, Applied Thermal Engineering 60 (1) (2013) 411-422.

[16] J. Ordonez, S. Yang, C. Ordonez, J. Vargas, T. Solano, M. Bublitz, E. Collins, Thermal simulation of an off-grid zero emissions building, in: ASME 2014 8th International Conference on Energy Sustainability collocated with the ASME 2014 12th International Conference on Fuel Cell Science, Engineering and Technology, American Society of Mechanical Engineers, 2014, pp. V002T06A005-V002T06A005.

[17] F. Dias, J. Souza, J. Ordonez, J. Vargas, R. Hovsapian, J. Amy, Notional all-electric ship thermal simulation and visualization, in: Electric Ship Technologies Symposium, 2009. ESTS 2009. IEEE, IEEE, 2009, pp. 539-546.

[18] J. Vargas, J. Souza, R. Hovsapian, J. Ordonez, T. Chiocchio, J. Chalfant, C. Chryssostomidis, E. Dilay, Notional all-electric ship systems integration thermal simulation and visualization, Simulation (2012) 0037549712441368.

[19] J. o'Rourke, Computational geometry in C, Cambridge university press, 1998.

[20] H. Childs, E. Brugger, B. Whitlock, J. Meredith, S. Ahern, D. Pugmire, K. Biagas, M. Miller, C. Harrison, G. H. Weber, H. Krishnan, T. Fogal, A. Sanderson, C. Garth, E. W. Bethel, D. Camp, O. Rübel, M. Durant, J. M. Favre, P. Navrátil, VisIt: An End-User Tool For Visualizing and Analyzing Very Large Data, in: High Performance Visualization-Enabling Extreme-Scale Scientific Insight, 2012, pp. 357-372. 
[21] S. Yang, E. Dilay, J. Ordonez, J. Vargas, J. Chalfant, Volume element model mesh generation strategy and its application in ship thermal analysis, Advances in Engineering Software 90 (2015) 107-118.

[22] P. J. Roache, K. N. Ghia, F. M. White, Editorial policy statement on the control of numerical accuracy, Journal of Fluids Engineering 108 (1) (1986) $2-2$.

[23] A. F. Mills, Basic heat and mass transfer, Pearson College Div, 1999.

[24] A. Bejan, Convection heat transfer, John wiley \& sons, 2013.

[25] J. A. Duffie, W. A. Beckman, Solar engineering of thermal processes, Vol. 3, Wiley New York etc., 1980.

[26] S. W. Churchill, H. H. Chu, Correlating equations for laminar and turbulent free convection from a vertical plate, International journal of heat and mass transfer 18 (11) (1975) 1323-1329.

[27] D. R. Flynn, B. A. Peavy, Thermal conductivity: proceedings, no. 302, US Dept. of Commerce, National Bureau of Standards.[For sale by the Supt. of Docs., US Govt. Print. Off.], 1968.

[28] E. J. Kansa, H. E. Perlee, R. F. Chaiken, Mathematical model of wood pyrolysis including internal forced convection, Combustion and Flame 29 (1977) 311-324.

[29] R. Burden, J. Faires, Numerical Analysis, Cengage Learning, 2010.

[30] A. Ben-Israel, A newton-raphson method for the solution of systems of equations, Journal of Mathematical analysis and applications 15 (2) (1966) $243-252$.

[31] D. R. Kincaid, E. W. Cheney, Numerical analysis: mathematics of scientific computing, Vol. 2, American Mathematical Soc., 2002. 
[32] R. C. Aiken, Stiff computation, Oxford University Press New York, Oxford, 1985.

[33] C. W. Gear, Numerical initial value problems in ordinary differential equations, Prentice Hall PTR, 1971.

[34] A. C. Hindmarsh, Odepack, a systematized collection of ode solvers, rs stepleman et al.(eds.), north-holland, amsterdam,(vol. 1 of), pp. 55-64., IMACS transactions on scientific computation 1 (1983) 55-64.

[35] W. Kays, A. London, Compact heat exchangers, 3rd (1984).

[36] M. J. Moran, H. N. Shapiro, D. D. Boettner, M. Bailey, Fundamentals of engineering thermodynamics, John Wiley \& Sons, 2010.

[37] J. Chalfant, B. Langland, S. Abdelwahed, C. Chryssostomidis, R. Dougal, A. Dubey, T. El Mezyani, J. Herbst, T. Kiehne, J. Ordonez, et al., A collaborative early-stage ship design environment, Tech. rep., ESRDC Technical reports (2012).

[38] R. Fang, W. Jiang, A. Monti, M. Zerby, G. Anderson, P. Bernotas, J. Khan, System-level dynamic thermal modeling and simulation for an all-electric ship cooling system in vtb, in: Electric Ship Technologies Symposium, 2007. ESTS'07. IEEE, IEEE, 2007, pp. 462-469.

[39] National Oceanic and Atmospheric Administration National Data Buoy Center, http://www.ndbc.noaa.gov/, [Online; accessed 2016/03/03].

[40] H. Babaee, J. Chalfant, C. Chryssostomidis, A. B. Sanfiorenzo, Systemlevel analysis of chilled water systems aboard naval ships, in: Electric Ship Technologies Symposium (ESTS), 2015 IEEE, IEEE, 2015, pp. 370-375. 
LaTeX Source Files
Click here to download LaTeX Source Files: LaTeX source files.zip

LaTeX Source Files
Click here to download LaTeX Source Files: LaTeX source files.zip Click here to download LaTeX Source Files: LaTeX source files.zip

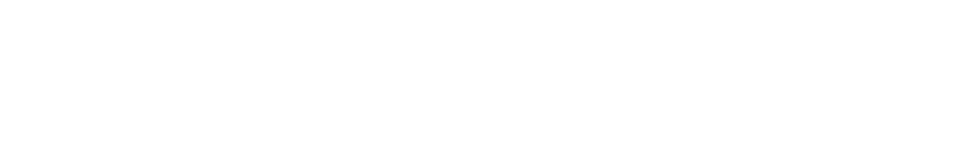

